\title{
The functional analysis of ABCG transporters in the adaptation of pigeon pea (Cajanus cajan) to abiotic stresses
}

\author{
Lili Niu Equal first author, 1, 2 , Hanghang Li ${ }^{\text {Equal first author, } 2 ~}{ }^{2}$ Zhihua Song ${ }^{2}$, Biying Dong ${ }^{2}$, Hongyan Cao ${ }^{2}$, Tengyue Liu ${ }^{2}$, \\ Tingting Du ${ }^{2}$, Wanlong Yang ${ }^{2}$, Rohul Amin ${ }^{2}$, Litao Wang ${ }^{2}$, Qing Yang ${ }^{1,2}$, Dong Meng ${ }^{\text {Corresp., 1, }, ~}$, Yujie Fu ${ }^{\text {Corresp. 1, 2, } 3}$ \\ ${ }^{1}$ Beijing Advanced Innovation Center for Tree Breeding by Molecular Design, Bei Jing, People's Republic of China \\ 2 The College of Forestry, Beijing Forestry University, Bei Jing, People's Republic of China \\ 3 Key Laboratory of Forestry Plant Ecology, Ministry of Education, Northeast Forestry University, Harbin, People's Republic of China \\ Corresponding Authors: Dong Meng, Yujie Fu \\ Email address: mengdongjlf@163.com, yujie_fu@163.com
}

ATP-binding cassette $(A B C)$ transporters are a class of proteins found in living organisms that mediate transmembrane transport by hydrolyzing ATP. They play a vital role in the physiological processes of growth and development in plants. The most numerous subtype transporter in the $A B C$ transporter family is the $A B C G$ group and which have the most complex function in a plant's response to abiotic stresses. Our study focused on the effect of ABCG transporters in the adaptation of the pigeon pea to adverse environments (such as drought, salt, temperature, etc.). We conducted a functional analysis of ABCG transporters in the pigeon pea and their role in response to abiotic stresses. A total of 51 $A B C G$ genes ( $C C A B C G s$ ) were identified, and phylogenetic analysis was conducted. We also identified the physicochemical properties of the encoded proteins, predicted their subcellular localization, and identified of the conserved domains. Expression analysis showed that $A B C G$ genes have different expression profiles with tissues and abiotic stresses. Our results showed that $C C A B C G 28$ was up-regulated at low temperatures, and $C C A B C G 7$ was up-regulated with drought and aluminum stress. The initial results revealed that ABCG transporters are more effective in the abiotic stress resistance of pigeon peas, which improves our understanding of their application in abiotic stress resistance. 
1 The functional analysis of ABCG transporters in the

2 adaptation of pigeon pea (Cajanus cajan) to abiotic

3 stresses

4

5 Lili Niu ${ }^{1,2,}$, , Hanghang $\mathrm{Li}^{2}$, ${ }^{*}$, Zhihua Song ${ }^{2}$, Biying Dong ${ }^{2}$, Hongyan $\mathrm{Cao}^{2}$, Tengyue Liu ${ }^{2}$,

6 Tingting $\mathrm{Du}^{2}$, Wanlong Yang ${ }^{2}$, Rohul Amin ${ }^{2}$, Litao Wang ${ }^{2}$, Qing Yang ${ }^{1,2}$, Dong Meng1, 2, \#, Yujie

$7 \mathrm{Fu}^{1,2,3, \#}$

8

$9 \quad{ }^{1}$ Beijing Advanced Innovation Center for Tree Breeding by Molecular Design, Beijing, People's

10 Republic of China

112 The College of Forestry, Beijing Forestry University, Beijing, People's Republic of China

$12{ }^{3}$ Key Laboratory of Forestry Plant Ecology, Ministry of Education, Northeast Forestry

13 University, Harbin, People's Republic of China

$14 *$ These authors contributed equally to this work.

16 Corresponding Author:

17 Dong Meng ${ }^{1,2}$, Yujie Fu ${ }^{1,2,3}$

18 The College of Forestry, Beijing Forestry University, Beijing 100083, People's Republic of

19 China

Email address: mengdongj1f@163.com (D.M.); yujie fu@163.com (Y.F.) 


\section{Abstract}

ATP-binding cassette $(\mathrm{ABC})$ transporters are a class of proteins found in living organisms that mediate transmembrane transport by hydrolyzing ATP. They play a vital role in the physiological processes of growth and development in plants. The most numerous sub-type transporter in the $\mathrm{ABC}$ transporter family is the $\mathrm{ABCG}$ group and which have the most complex function in a plant's response to abiotic stresses. Our study focused on the effect of ABCG transporters in the adaptation of the pigeon pea to adverse environments (such as drought, salt, temperature, etc.). We conducted a functional analysis of ABCG transporters in the pigeon pea and their role in response to abiotic stresses. A total of $51 A B C G$ genes ( $C c A B C G s)$ were identified, and phylogenetic analysis was conducted. We also identified the physicochemical properties of the encoded proteins, predicted their subcellular localization, and identified of the conserved domains. Expression analysis showed that $A B C G$ genes have different expression profiles with tissues and abiotic stresses. Our results showed that $C C A B C G 28$ was up-regulated at low temperatures, and $C C A B C G 7$ was up-regulated with drought and aluminum stress. The initial results revealed that $\mathrm{ABCG}$ transporters are more effective in the abiotic stress resistance of pigeon peas, which improves our understanding of their application in abiotic stress resistance.

\section{Introduction}

ATP-binding cassette (ABC) transporters are a part of the largest and oldest known protein families and are widely found in eukaryotic and prokaryotic organisms (Martinoia et al., 2002; Mosser et al., 1993). ABC transporters play a crucial role in the growth and development of plants by detoxifying exogenous toxins in response to abiotic stress, and transporting metabolites including intercellular peptides, sugars, lipids, alkaloids, inorganic ions and other metabolic substances (Mendez \& Salas, 2001; Morris \& Zhang, 2006; Mourez et al., 1997). AtABCB1 (also known as AtMDR1) was first identified in Arabidopsis in 1992 (Dudler \& Hertig, 1992). ABC transporters are divided into eight subfamilies in the plant genome (ABCA-ABCG and ABCI) according to the Human Genome Organization (HUGO). There are 129 ABC transporters identified in Arabidopsis genomes (Arabidopsis thaliana), 128 identified in rice genomes (Oryza sativa), and 261 identified in soybean (Glycine max) genomes (Mishra et al., 2019; Schulz \& Kolukisaoglu, 2006; Sanchez-Fernandez et al., 2001).

The ATP-binding cassette subfamily $\mathrm{G}$ is the largest subfamily of the ABC transporter family. The ABCG protein is widely distributed in plants and plays an important role in many fundamental physiological processes (Kretzschmar et al., 2011). Highly conservative amino acids, including 1-2 nucleotide-binding domains (NBDs), a highly hydrophobic transmembrane 
59 domain, and 1-2 trans-membrane domains (TMDs) are typical structural features of ABCG 60 transporters (Verrier et al., 2008). The ABCG subfamily was divided into white-brown 61 complexes (WBCs) and pleiotropic drug resistance (PDRs) complexes. WBCs are semi62 molecular ABCG transporters that contain one NBD domain and one TMD domain. PDRs 63 belong to the full-molecule ABCG transporter and include two NBD domains and two TMD domains (Jasinski et al., 2009). The NBD domain consists of three highly conserved regions of approximately 200 amino acids and include the Walker A box [ $\left.\mathrm{GX}_{4} \mathrm{GK}(\mathrm{ST})\right]$, Walker B box $\left[(\mathrm{RK}) \mathrm{X}_{3} \mathrm{GX}_{3} \mathrm{~L}\right.$ (hydrophobic) 3 ], and Walker $\mathrm{C}$ and are approximately 120 amino acids in length (J. E. Walker, 1982). The TMD domain contains 4-6 $\alpha$-helixes, which are the channel for the transport of substrate molecules for transmembrane transport (Hyde et al., 1990; Schneider \& Hunke, 1998). It is generally believed that the mechanism of ABCG transporters occurs on the substrate recognition site on the TMD domain and works to recognize and bind transport substrates located near the cell membrane. The NBD domain on the cell membrane hydrolyzes ATP to provide energy for substrate transport and causes conformational changes in the membrane structure (Davidson \& Maloney, 2007). SpTUR2, the first full-molecule $A B C G$ transporter gene in plants, was identified in the perennial aquatic plant Spirodella polyrhiza in 2002 (van den Brule et al., 2002). More than 40 ABCG transporters have been identified in Arabidopsis, rice, and soybean genomes, to date. ABCG transporters are involved with the plant's many physiological activities. For example, $O s A B C G 31$ in rice may decrease evaporation from plant leaves and may be related to the drought stress response of rice (Chen et al., 2011). Arabidopsis AtPDR8 is involved with $\mathrm{Na}^{+}$excretion, increasing the plant's tolerance to salt and drought stress (Kim et al., 2007). AtPDR36 also responds to the toxic heavy metal effects in Arabidopsis thaliana and participates in the stomatal self-regulation in leaves (Kim et al., 2010).

Cajanus cajan (L.) Millsp, also known as pigeon pea, is a diploid plant $(2 \mathrm{n}=22)$ with a genome size of approximately $858 \mathrm{Mbp}$. It grows in tropical and subtropical regions and has a stable regulatory system to adapt to conditions that include high temperature, high salinity, and drought (Singh et al., 2013; Varshney et al., 2011; Wu et al., 2011; Yadu et al., 2018). Cooler environmental temperatures have led to the northern migration of the pigeon pea. The pigeon pea grows easily in acidic soil ( $\mathrm{pH} \mathrm{5-7)}$ and is resistant to aluminum, which has bought it much attention. The numerous secondary metabolites of the pigeon pea play an important role in the adaptation of the plant to its adverse environment (Shepherd, 1986). It also possesses medicinal properties and is used widely in the chemical industry (Ogoda et al., 2002; Pandey \& Pandey, 1991).

Our research focuses on the trans-membrane transport of secondary metabolites, antibiotics, and heavy metal ions by ABCG transport protein hydrolysis of ATP (Yazaki, 2006; Badri et al., 
94

2008; Le Hir et al., 2013; Fourcroy et al., 2014). The inhibition of ABCG transporters decreases plant flavonoid content (Morris \& Zhang, 2006; Imai et al., 2004). Plants that transport some hormones (such as ABA) can improve their survivability in drought and other adverse conditions (Kuromori et al., 2010; Kang et al., 2010). ABCG transporters could positively affect a plant's response to adversity by transporting specific substances. We identified family genes, and conducted phylogenetic and expression analyses to reveal the important role of ABCG transporters in resisting environmental stress in the pigeon pea. A total of 51 ABCG transporters were identified and further analyzed. We found cis-acting elements related to the stress response in several genes identified above, suggesting that the ABCG transporter had a related regulatory effect in the pigeon pea. We analyzed the expression of the ABCG gene in different organs and different stress treatments and observed the tissue specificity of the ABCG gene and stress expression response to explore the expression profile of the ABCG gene in the pigeon pea. Our results provide scientific support for exploring the mechanism of ABCG transporters in relation to the resistance of several abiotic stressors of the pigeon pea.

\section{Materials and Methods}

\section{Identification of $A B C G$ transporters in the pigeon pea genome}

One hundred-twenty nine Arabidopsis ABC protein sequences were downloaded from the Phytozome v12.1 database (https://phytozome.jgi.doe.gov/pz/portal.html). All of the Arabidopsis ABCs were used to identify the ABC transporters in the Cajanus cajan (L.) Millsp (taxid: 3821) database using BLASTP search in the National Center for Biotechnology Information (NCBI) with an initial cut-off e-value of $1.0 \mathrm{e}^{-10}$ and max target sequence of 500. The Hidden Markov Model (HMM) profiles of ABC transporters (such as PF00005, PF00664, and PF10614) were downloaded from the Pfam database (http://pfam.xfam.org/search\#tabview=tab1) and the HMMER search server was used against the pigeon pea proteome with an E-value setting of 1.0 $\mathrm{e}^{-5}$ (https://www.ebi.ac.uk/Tools/hmmer/) (Potter et al., 2018). The resulting protein sequences were further identified by a conserved domain of $\mathrm{ABC}$ based on a conserved domain search (CD-search) on the NCBI website with a threshold e-value of $1.0 \mathrm{e}^{-5}$. We identified members of the $\mathrm{ABC}$ transporters using the above approach.

Multiple-sequence alignments were performed on the $\mathrm{ABC}$ transporters identified above and several ABC proteins of Arabidopsis thaliana, rice, and soybean, using clustalW with default settings. The ABC transporters' phylogenetic tree was constructed using the neighborjoining (NJ) method with 1000 replications of bootstrap and p-distance of a model in MEGA6.0 (https://www.megasoftware.net/) (Tamura et al., 2013). The phylogenetic tree was visualized 
using the iTOL website (http://itol.embl.de/help.cgi) (Sugiyama et al., 2007). Finally, ABCG transporters were identified through the phylogenetic analysis of the $\mathrm{ABC}$ family of the pigeon pea.

\section{Phylogenetic tree construction and chromosome localization}

The $A B C G$ genes' chromosomal information was obtained through the NCBI website (https://www.ncbi.nlm.nih.gov/) and were systematically named based on the number and relative position of the $A B C G$ genes in the pigeon pea chromosome. The phylogenetic tree of the pigeon pea ABCG transporters was constructed in MEGA6.0, as described above.

The chromosomal location of the $C c A B C G s$ was mapped using the MapChart software (https://www.wur.n1/en/show/Mapchart.html) based on the chromosomal location information of the ABCG transporters (Voorrips, 2002).

\section{Protein property prediction, subcellular localization}

The exon information of $C C A B C G s$ was collected on the NCBI website. The number of amino acid sequences, relative molecular weight, and the isoelectric point (pI) of CcABCGs was predicted in the ExPASy ProtParam server database (http://expasy.org/). We predicted the subcellular localization of ABCG proteins using the Cell-PLoc 2.0 database (http://www.csbio.sjtu.edu.cn/bioinf/Cell-PLoc-2/) (Chou \& Shen, 2008).

To verify our predictions of subcellular localization, two-week-old pigeon pea seedlings were used as a cDNA template to amplify the full-length coding region of the $C c A B C G 7$ gene. The primers were: F: 5'-ATGGTGATGATATGGGAAAATGTTAC-3' and R: 5'TTATATTGGAAGGTTTGGGGACA-3'. The recovered PCR production was ligated to the T vector pMD19-T (TaKaRa, Japan). Subsequently, it was cloned into the eGFP-pROK II vector by double digestion using Kpn I /Xba I to construct the CcABCG7-eGFP-pROK II expression vector, and was transformed into the agrobacterium strain GV3101 (Shanghai Weidi Biotechnology, China). One-month-old tobacco seedlings were injected into the agrobacterium liquid on the back of tobacco leaves with a disposable syringe and placed in the dark for 3 days for observation. Approximately $0.5 \mathrm{~cm}^{2}$ of the material was taken around the injection site, observed, and photographed under a Leica SP8 laser confocal microscope (Leica, Germany).

\section{Analysis of motifs and conserved domain}

To examine the characteristics and properties of the pigeon pea $A B C G$ subfamily protein domain, the conserved motif of CcABCGs was analyzed on the MEME software (http://meme- 
158

159

160

161

162

suite.org/tools/meme) with following parameters: the number of motifs was set 10 and the optimum motif width was set between 20 and 200, the other parameters were set to their default (Bailey \& Elkan, 1994). Then InterPro program (http://www.ebi.ac.uk/interpro/scan.html) was used to annotate all 10 motifs.

The conserved domain of CcABCGs was performed using the HMMER servers (https://www.ebi.ac.uk/Tools/hmmer/) and visualized with TBtools software (Chen, 2018). We selected representative WBC and PDR transporter amino acid sequences as target sequences and chose the template with higher homology and better coverage using the Swiss-model server set to automatic (https://swissmodel.expasy.org/interactive). The model results were evaluated using the SAVES server (https://servicesn.mbi.ucla.edu/SAVES/), and the homology model of the CcABCG proteins was visualized by the PyMol software.

\section{Gene structure and cis-elements analysis of CcABCGs}

The intron/exon structures of the $A B C G$ genes were analyzed using the gene annotation file (GFF), C.cajan_V1.0, and visualized using TBtools software (Chen, 2018), based on the evolution analysis of $C c A B C G s$. The 2,000 bp upstream region of all identified $C c A B C G s$ was extracted from the pigeon pea genome to identify the stress-related or other functional cis-acting regulatory elements of the promoter sequences using TBtools software. All promoter sequences were analyzed using PlantCARE software (http://bioinformatics.psb.ugent.be/webtools/plantcare/html/) (Rombauts et al., 1999).

\section{GO annotation and function prediction}

GO (Gene Ontology) integrates and unifies the description and standards of gene products in a database and provides the most comprehensive description of gene functions and gene products. The ABCG protein sequences in the pigeon pea were used for blast alignment in the Swiss-prot database (https://www.uniprot.org/blast/) and the alignment results were annotated and classified by the pigeon pea $A B C G$ gene (Ashburner et al., 2000; Consortium, 2019; Ehlert et al., 2006; Yang et al., 2016).

\section{Plant materials and treatments}

Pigeon pea seeds (ICPL87119) were sown in a soil mixture of nutrient soil, vermiculite, and perlite (1:1:1) in the greenhouse at Beijing Forestry University in China with natural light for 10$14 \mathrm{~h}$ /day, a temperature of $18-28^{\circ} \mathrm{C}$ and a relative humidity of $45-70 \%$. After three months, the roots, stems, leaves, and flowers from pigeon pea trees were selected and stored at $-80^{\circ} \mathrm{C}$ to extract RNA and further analyze their tissue-specific expression. 
The pigeon pea seeds were surface-sterilized with $75 \%$ ethanol for 30 seconds, then soaked in sodium hypochlorite solution for 6 minutes, and finally washed 5 times with sterile water for 30 second durations. These sterilized seeds were grown in Murashige and Skoog (MS) medium at $\mathrm{pH}=5.8$ in growth chambers at $24 \pm 2^{\circ} \mathrm{C}$ with a photoperiod of $16 \mathrm{~h}$ light $/ 8 \mathrm{~h}$ dark, $400 \mu \mathrm{M} \mathrm{m}^{-2}$ $\mathrm{s}^{-1}$ light intensity. To analyze the expression of the $C c A B C G$ genes in various abiotic stresses, the 14-day old pigeon pea seedlings were assigned to different treatments. The treatments were as follows: heat and cold stress, in which the seedlings were cultured at $4{ }^{\circ} \mathrm{C}$ and $42^{\circ} \mathrm{C}$ in incubators, respectively; salt and metal stress, in which the seedlings were grown in solid MS medium with $200 \mathrm{nmol} / \mathrm{L} \mathrm{NaCl}$ and $100 \mu \mathrm{mo} / \mathrm{L} \mathrm{AlCl}_{3}$, respectively; drought stress, in which the pigeon pea seedlings were treated with $250 \mathrm{nmol} / \mathrm{L}$ mannitol in solid MS medium. The roots and leaves of these seedlings were sampled at $0 \mathrm{~h}, 6 \mathrm{~h}$, and $12 \mathrm{~h}$ after various treatments. Three biological replicates of each sample were immediately frozen in liquid nitrogen and stored at $80^{\circ} \mathrm{C}$ until expression analysis of variously abiotic stresses was conducted.

\section{RNA isolation and quantitative real-time PCR analysis}

We selected 10 genes containing elements that responded to adversity for tissue specificity analysis and abiotic stress analysis based on the above analysis of cis-elements in the promoter region. Total RNA was isolated using the CTAB method and first-strand cDNA was synthesized from $1 \mu \mathrm{g}$ of total RNA using a PrimeScript RT kit (Takara) according to the manufacturer's instructions. The quality and concentration of cDNA were assessed using a Nano Photometer N50 (Implen GmbH, Munich, Germany). We performed expression analysis of the ABCG transporter under different tissues and abiotic stresses using qRT-PCR. Real-time RT-PCR analysis was performed using CFX connect (Bio-Rad, California, USA) with the SYBR Green PCR Master Mix (TaKaRa, Tokyo, Japan) with CcActin as a reference gene. The gene primers selected were synthesized on the Sangon Biotech website (http://www.sangon.com/newPrimerDesign) and are shown in Table S1. All analyses were performed with three biological replicates and qRT-PCR data was analyzed using IBM SPSS 22 software (IBM Corporation, USA).

\section{Results}

\section{Identification of ABCG transporter genes in the pigeon pea genome}

One hundred-twenty nine Arabidopsis ABC proteins were downloaded and used as queries in the pigeon pea genome database using BLASTP server to identify all members of the pigeon pea ABCG transporters. A total of $222 \mathrm{ABC}$ proteins were identified in the pigeon pea after removing redundancies. The HMMER search was performed using the HMM of ABC 
223

224

225

226

227

228

229

230

231

232

233

234

235

236

237

238

239

240

241

242

243

244

245

246

247

248

249

250

251

252

253

254

255

transporters (such as PF00005, PF00664, and PF10614) to screen for ABC transporters identified by BLASTP. One hundred fifty-five ABC proteins were eventually confirmed to have NBD/TMD domains (Table S2). To explore the phylogenetic evolutionary relationship between the pigeon pea and other species including Arabidopsis, rice, and soybean, a Neighbor-Joining (NJ) tree was constructed (Fig. S1) based on ABC proteins. A phylogenetic relationship indicated that the pigeon pea $A B C$ gene family was classified into 8 different groups (ABCA$\mathrm{ABCI}$ ), and the ABCG subfamily, which contained 51 members, was the largest group of $\mathrm{ABC}$ transporters in the pigeon pea.

\section{Phylogenetic tree construction and chromosome localization}

All of the ABCG transporters identified above were named $C C A B C G 1-C c A B C G 51$ based on their chromosomal location. A Neighbor-Joining (NJ) tree was constructed to analyze the phylogenetic relationship of ABCG transporters (Fig. 1). Phylogenetic analysis indicated that the ABCG transporters were further divided into WBC and PDR, in which WBC contained 33 ABCG transporters and PDR contained 18 transporters.

The chromosome localization of ABCG transporters was determined in the pigeon pea genome and all identified $C C A B C G s$ were found to be diversely distributed on pigeon pea chromosomes, except for chromosome 7. Chromosomes 1 and 8 both contained one ABCG transporter and all chromosomes of the pigeon pea had the least ABCG transporters.

Chromosomes 2, 9, and 11 included 5, 5, and 8 transporters, respectively. Seventeen genes were distributed on unplaced scaffolds and were mapped into a single chromosome, ChrUn (Fig. 2). Two pairs of genes ( $C c A B C G 8 / 9, C c A B C G 32 / 33)$ were closely linked on the chromosome and belonged to the paralogous genes. The $A B C G$ gene locations were annotated using the NCBI website and the information in shown in Table 1.

\section{Protein property prediction, subcellular localization of CcABCGs}

Fifty-one CcABCGs were identified and their protein properties) were predicted (Table 1), including their amino acid lengths, relative molecular weights, and isoelectric points (pIs).

Results indicated that the lengths of all $\mathrm{ABCG}$ proteins ranged from 609 aa (CcABCG34) to 1500 aa (CcABCG29). Similarly, their relative molecular mass ranged from $68159.95 \mathrm{Kd}$ (CcABCG34) to $170370.83 \mathrm{Kd}(\mathrm{CcABCG} 29)$ and the theoretical isoelectric points ranged from 6.75 (CcABCG29) to 9.47(CcABCG4). The $A B C G$ genes' exon numbers changed from 1 to 26.

We performed the subcellular localization of CcABCGs to determine the active sites of the CcABCGs. The prediction of the subcellular localization indicated that all CcABCGs were localized in the cell membrane. Three ABCG transporters (CcABCG26, 28, 29) were found to be 
256

257

258

259

260

261

262

localized in the chloroplast and not just on the cell membranes (Table 1). To confirm our prediction, we verified the subcellular localization of the ABCG transporter by transiently expressing $C c A B C G 7-e G F P$ in tobacco leaves. The results showed that the green fluorescent signal of CcABCG7-eGFP-pROK II was mainly detected in the cell membrane (Fig. S2).

\section{Analysis of motifs and conserved domain of CcABCGs}

To identify the structure and function of the ABCGs in the pigeon pea, motif analysis was performed based on the phylogenetic analysis (Fig. 3A). A total of 10 conserved motifs were predicted and the width of those motifs ranged from 32 to 123 amino acids. The number of motifs in each amino acid varied from 2 to 10 . Results showed that the number of motifs in the WBC was significantly less than the number of motifs detected in the PDR. All 10 motifs were annotated using the InterPro program to identify the motif structure. Annotation analysis demonstrated that Motifs 3, 7, 9, and 10 did not annotate at all; Motif 6 and Motif 8 annotated in the ABC_2_trans structure (IPR013525); Motif 1,2,4,5 annotated in the P_loop_NTPase structure (IPR027417); Motifs 1, 4, and 5 were annotated in the ABC_transporter_like structure (IPR003439). Our results indicated that the motifs of the same annotation were relatively conservative in structure, such as Motifs 1, 4, and 5 (Table S3).

We examined the conserved domain of CcABCGs to explore the ABCG transporter's domain function using HMMER servers (Fig. 3B). The HMME model, "ABC2_membrane" indicated the TMD domain, and "ABC_tran" indicated the NBD domain. The results showed that the ABCG transporters were different from other members of the ABC transporter family with an inverted "TMD-NBD" domain arrangement pattern. All ABCG transporters contained the NBD domain, but several ABCG transporters did not contain the TMD domain. The WBC subgroup contained one NBD domain with a length that increased from 97 to 153 and one or no TMD domains with a length of approximately 200, while the PDR subgroup contained two NBD domain with an amino acid length of 138 to 200 and a domain approximately 200 TMD long.

CcABCG35 was selected for homology modeling to explore the molecular functions of CcABCGs. The best template of CcABCG35 was 6hij.1A (Seq Identity:33.05\%, GMQE:0.58, Coverage:0.85) using the Swiss-model program. According to the PROCHECK evaluation results, Ramachandran Plot results in the model evaluation revealed that in each ABCG model > $90 \%$ of the amino acid residues were distributed in the allowed region, indicating that the quality of the CcABCG protein model obtained by homology modeling was reliable (Fig. S3A). A model of CcABCG35 revealed that Walker A and Walker B were located in the NBD domain, while the TMD domain contained six alpha helices (Fig. S3B).

\section{Gene structure and cis-elements analysis of CcABCGs}


Gene structure was analyzed based on the phylogenetic relationship of the ABCG gene family to better understand their structural evolution (Fig. 4A). The highly conserved exon sequence is an essential sequence for the ABCG transporter to perform gene functions, and the differences in introns may be based on dissimilar regulatory mechanisms for the existence of genes. The results indicated that all ABCG transporters in the pigeon pea contained different numbers of exons and introns. The number of exons in CCPDRs was significantly higher than that in $C c W B C s$. The number of exons of $C c P D R s$ ranged from 5 to 25, while the number of exons of $C c W B C s$ varied from 1 to 14 and there were large differences in the number of introns. There were approximately 20 introns in CcPDRs and about 5 in CcWBCs.

A 2,000 bp region upstream of the promoter was selected for analysis of the cis-acting element of the pigeon pea ABCG gene family in order to explore the expression elements of the promoter region (Fig. 4B). Three cis-acting elements were screened, and focused on hormoneresponsive elements, light-responsive elements, and stress-responsive elements. The number of light-responsive elements in the promoter region of the pigeon pea ABCG transporter was found to be relatively large. Hormonal response elements had a large number of copies in the promoter region of the ABCG transporter, including auxin response elements (AuxRR-core, TGAelement, etc.) and gibberellin response elements. There were fewer stress response elements than hormone response elements and some genes did not contain stress response elements (CCABCG14, CcABCG10, etc.). Drought-related cis-acting elements were identified simultaneously in $C C A B C G 7$ and $C C A B C G 24$. Low-temperature stress-related cis-acting elements (LTR) were identified in $C c A B C G 28$ and their elements were highly conserved with short sequences composed of CCGAAA.

\section{Go annotation and function prediction}

The $A B C G$ gene in pigeon pea was annotated and divided into three categories: molecular function, biological processes, and cell components. The annotation results showed that all 50 genes were annotated into three major categories, but CcABCG48 did not show results from the blast alignment method and UniProtKB ID and all other usable data are provided in Raw Data S5. The transmembrane transport (GO:0055085) had the highest prominence and 45 genes were annotated in the transmembrane transport. CcABCG28 and CcABCG29 were blasted in AB36G_ARATH (UniProtKB ID), and annotated in 42 GO annotations, which included "response to salt stress" (GO:0009651) and "root development" (GO:0048364). Fifty $A B C G$ genes were annotated to the broad category of molecular functions related to ATPase activity and ATP binding. The major category of cellular components found most of the $A B C G$ genes to be annotated on the membrane (Fig. 5). 
324

325

326

327

328

329

330

331

332

333

334

335

336

337

338

339

340

341

342

343

344

345

346

347

348

349

350

351

352

353

354

355

356

\section{Expression analysis of the pigeon pea ABCG gene family in different organs}

To explore the expression pattern of the ABCG gene in different organs during the growth and development of pigeon peas, the organs (roots, stems, leaves, and flowers) of one-year-old pigeon peas were collected to extract RNA for qRT-PCR analysis for the expression of the ABCG genes. Tissue-specific expression analysis found that the expression of ABCG transporters in different tissues was not significantly different. However, there was an obvious difference in the expression level of the ABCG transporter gene in flowers, which was significantly lower than that in the roots, stems, and leaves. The expression of $C c A B C G 24$ was significantly higher than that of any other gene (Fig. 6).

\section{Expression analysis of the pigeon pea ABCG transporters under different abiotic stresses}

To explore the expression level of the pigeon pea $A B C G$ gene family under different abiotic stresses, two-week-old pigeon pea seedlings were selected and transplanted into the culture environments at $4{ }^{\circ} \mathrm{C}, 42^{\circ} \mathrm{C}, 200 \mathrm{nmol} / \mathrm{L} \mathrm{NaCl}, 100 \mu \mathrm{mol} / \mathrm{L} \mathrm{AlCl}_{3}$ and $250 \mathrm{nmol} / \mathrm{L}$ mannitol in solid MS medium, respectively. $C C A B C G 5,7,14,19,21$ belonged to the WBC subgroup, and $C C A B C G 10,24,28,29,32$ belonged to the PDR subfamily. We found that the expression difference of 10 genes in the roots was significantly higher than in the leaves (Fig. 7).

The two major subfamilies of ABCG transporters had significant differences in expression in the roots (Fig. 7A, C, E, G, I) under $4^{\circ} \mathrm{C}$ stress and $\mathrm{NaCl}$ stress. The $P D R$ family genes were significantly up-regulated under both stressors. $C$ CABCG24 was up-regulated 40-fold after $12 \mathrm{~h}$ at $4^{\circ} \mathrm{C}$ and $C c A B C G 28$ increased 65 times. Under the initial $\mathrm{NaCl}$ treatment, $C c A B C G 24$ increased 10 times. However, it is worth noting that with an increase of the treatment time, the expression of $C C A B C G 24$ decreased to below the initial level at $12 \mathrm{~h}$. We found that the relative expression changes of the WBC subgroups under drought and aluminum stress treatments were opposite, as shown in Fig. 7E, G. The expression level of CcABCG5 increased under drought stress at $6 \mathrm{~h}$ but did not change significantly under aluminum stress. $C c A B C G 19$ also exhibited the same pattern of opposite expression in the treatments of mannitol stress and $\mathrm{AlCl}_{3} \mathrm{stress}_{\text {. }}$ Under high-temperature stress, we observed that the expression of $C c A B C G 7$ was downregulated but the expression of $C C A B C G 7$ in leaves was up-regulated.

There was a relatively mild difference in the expression levels in leaves (Fig. 7B, D, F, H, J). $C C A B C G 28$ experienced up-regulation under $4^{\circ} \mathrm{C}$ treatment. However, $C c A B C G 7$ was significantly up-regulated after $6 \mathrm{~h}$ of drought stress. In the same situation, $C c A B C G 7$ was upregulated 11.3 times after $12 \mathrm{~h}$ of aluminum stress treatment. However, under sodium stress, 
$C c A B C G 7,19,21$ were down-regulated. The ABCG transporter was found to have different expressions in response to different environmental stresses.

\section{Discussion}

$\mathrm{ABC}$ transporters are found in animals and plants and have a large number of complex biological functions. A total of $155 \mathrm{ABC}$ transporters were identified in the pigeon pea genome, which were divided into 8 subgroups of ABCA-ABCI (Fig. S1). Among them, the ABCE and $\mathrm{ABCF}$ subfamily had no transport function because their proteins were localized to the endoplasmic reticulum without a transporter region. The ABCB subfamily may be involved in the transport of auxins, secondary metabolites, and heavy metal salts (Kang et al., 2011; Verrier et al., 2008). The ABCC subfamily may be involved in plant chlorophyll transport and cell detoxification among other functions (Hashimoto \& Yamada, 2003). The ABCG transporters contained 51 members and was the largest group of ABC transporters in the pigeon pea, which was larger than reported for Arabidopsis (44) and rice (50), but smaller than the 116 members of ABCG reported in soybean (Mishra et al., 2019; Jasinski et al., 2003).

As shown in Fig. 1, the ABCG subfamily could be further divided into a full-molecular transporter PDRs and a semi-molecular transporter WBCs, in which PDRs contained 18 ABCG transporters and WBCs included 33 ABCG transporters. The conserved domain of the ABCG transporter is composed of NBD and TMD, and the ABCG transporter is different from the conserved domain arrangement of other $\mathrm{ABC}$ transporter subfamilies. The conserved domain composition of the ABCG transporter is a trans-TMD-NBD structure (Fig. 3)(van den Brule \& Smart, 2002). The arrangement of ABC domains and their transmembrane domains are highly conserved, while the number of transmembrane helixes and their arrangements is not necessarily conserved, and determines their functional differences (Andolfo et al., 2015; Goodman et al., 2004; Locher, 2004). ABCG transporters are involved in many physiological activities of plants, including the transport of small molecular compounds, secondary metabolites, and are active in disease resistance, hormonal regulation, and adaptation to changes in the external environment (Alejandro et al., 2012; Bird et al., 2007; Lee et al., 2010). Arabidopsis cutin and wax secretion require the participation of AtWBC11 (Panikashvili et al., 2007). Rice OsPDR9 could be induced by methyl jasmonate, and AtPDR 8 could be induced by salicylic acid (Kim et al., 2007; Kuromori et al., 2010; Moons, 2008). External stressors on plants cause the signal receptors on plant cells to first sense the external stress signal and produce a second messenger transmitted inside the cell, such as $\mathrm{Ca}^{2+}$, reactive oxygen and ABA. The stress response also mediates proteins, causing phosphorylation to activate downstream transcription factors and stress-related target genes, thereby resisting the destruction of plant cells. (Mittler et al., 2012; Farooq et al., 
391

392

393

394

395

396

397

398

399

400

401

402

403

404

405

406

407

408

409

410

411

412

413

414

415

416

417

418

419

420

421

422

423

424

425

2009). Many $A B C G$ genes annotated hormone transport and regulation-related functions (Fig. 4B and Fig. 5). AtABCG22 was induced by drought stress, possibly by affecting the stomata and increasing transpiration (Kuromori et al., 2011). In our study, CcABCG28(PDR) may be involved in the response to abiotic stresses including colder temperatures and salinity, while $C c A B C G 7(\mathrm{WBC})$ in the pigeon pea tended to respond to drought and aluminum stress, as shown in Fig. 7.

The analysis of the location of the ABCG family in the pigeon pea chromosome found that most of the $A B C G$ gene was located on chromosome 11, as shown in Fig. 2. The major part of most plant genomes consisted of different repeating DNA elements. These sequence elements are essential for the large-scale organization and evolution of the plant genome (Kubis et al., 1998). Our results showed that there were two pairs of paralogous genes (CCABCG8/9,

$C c A B C G 32 / 33$ ) closely linked to chromosome 3 and chromosome 11, and the tandem replication led to the expansion of these two genes. Introns are important components in the genome of eukaryotes. The typical 5'-GT $\cdots$ AG-3'of intron is an important marker of gene splicing and an important feature of introns in eukaryotic mRNA sequences (Rose et al., 2016; Mukherjee et al., 2018). We performed exon/intron analysis of the ABCG transporter to determine the stress regulation of the splicing process in Fig. 4A. Our results indicated that PDR contained more intron structures than WBC. It is thought that PDR had more variable splices and functions and may respond more frequently to stress. Furthermore, introns may also affect gene expression, and more introns may have a stronger regulatory effect (Rose et al., 2016; Mukherjee et al., 2018). There is no evidence supporting the theory that more exons make them prone to more regulation. PDR/WBC have different regulatory effects, which depends on deeper molecular mechanisms. The cis-acting elements are involved in the binding of transcription factors (TF) and regulate the expression of the gene (Toledo et al., 2011). Our study found that there were many low temperature-related elements in the promoter region of the pigeon pea, which might be induced by chilling in the pigeon pea (Fig. 4B). The promoter region of the pigeon pea ABCG transporter had a large number of hormone-regulated expression elements (abscisic acid responsiveness, MeJA responsiveness), which also demonstrated the important role of ABCG transporters in the regulation of plant hormones (Kuromori et al., 2010b; Wu et al., 2007). Kuromori et al. (2011) found that AtABCG25 is mainly expressed in vascular tissues and can transport ABA out of cells.

ABC transporters are essential for plant development and play a role in the processes of gametogenesis, seed development, seed germination, organ formation, and secondary growth (Thanh, etc, 2018). We performed expression analysis of the pigeon pea in different organs and under different abiotic stresses (Fig. 6 and Fig. 7). The expression levels of all genes in flowers 
426

427

428

429

430

431

432

433

434

435

436

437

438

439

440

441

442

443

444

445

446

447

448

449

450

451

452

453

454

455

456

457

were not overtly different than in other tissues, while $C C A B C G 24$ was more highly expressed in other tissues. $C c A B C G 24$ was expressed in the stems of pigeon peas in significantly higher amounts than in other tissues, showing that $\mathrm{ABCG}$ transporters are found in active regions such as trans-membrane proteins. AtABCG25 is mainly expressed in vascular tissues, can transport ABA to outside of cells (Kuromori et al., 2011), and is closely related to the formation of plant vascular bundles. We showed that the expression of most genes in the roots was significantly higher than that in the leaves by analyzing the expression levels of the pigeon seedlings under different stresses. Interestingly, the expression of $C c A B C G 28$ is up-regulated, regardless of any tissue (root or leaf), especially in the leaves. The up-regulation of this expression is significantly higher than any other gene under low-temperature stress. At present, the regulation mechanism of the $C C A B C G 28$ homologous gene in other species is still unclear, but it was shown to play an important role in the growth and development of the pigeon pea. We also found that $C c A B C G 24$ was highly expressed under $\mathrm{NaCl}$ treatment, and its homologous gene AtPDR 12 was of great significance for $\mathrm{Pb}$ (II) resistance in Arabidopsis (Lee et al., 2005). CcABCG24 played an important role in response to salt stress in this experiment. In response to drought and salt stress in plants, the cuticle lipid coding ABCG transporter gene was significantly up-regulated, indicating that the $\mathrm{ABCG}$ transporter has an important role in adapting plants to drought and saline-alkali environments (Luo et al., 2007; Panikashvili et al., 2007b). The expression level of $C C A B C G 7$ was up-regulated in pigeon pea roots under drought and aluminum stress, which proved its important role in stress tolerance.

\section{Conclusions}

A total of 51 ABCG transporters were identified and divided into two subgroups: WBC and PDR. We analyzed the protein structure and gene structure cis-elements on the pigeon pea ABCG transporters. The highly conserved NBD domain determines the important function of the ABCG transporter. $C c A B C G 28$ was significantly up-regulated under low temperature stress, while $C c A B C G 7$ responded to drought stress. In conclusion, our results reveal the role of $\mathrm{ABCG}$ transporters in abiotic stress resistance and broaden the research direction in abiotic stress resistance of pigeon peas.

\section{Acknowledgments}

The authors gratefully acknowledge the support of The College of Forestry, Beijing Forestry University. and Beijing Advanced Innovation Center for Tree Breeding by Molecular Design.

\section{References}


458 Alejandro, S., Lee, Y., Tohge, T., Sudre, D., Osorio, S., Park, J., Bovet, L., Lee, Y., Geldner, N., 459 Fernie, A.R., and Martinoia, E. 2012. AtABCG29 is a monolignol transporter involved in lignin 460 biosynthesis. CURRENT BIOLOGY 22:1207-1212. 10.1016/j.cub.2012.04.064

461 Andolfo, G., Ruocco, M., Di Donato, A., Frusciante, L., Lorito, M., Scala, F., and Ercolano, M.R. 462 2015. Genetic variability and evolutionary diversification of membrane ABC transporters in plants. BMC PLANT BIOLOGY 15:51. 10.1186/s12870-014-0323-2

Ashburner, M., Ball, C.A., Blake, J.A., Botstein, D., Butler, H., Cherry, J.M., Davis, A.P., Dolinski, K., Dwight, S.S., Eppig, J.T., Harris, M.A., Hill, D.P., Issel-Tarver, L., Kasarskis, A., Lewis, S., Matese, J.C., Richardson, J.E., Ringwald, M., Rubin, G.M., and Sherlock, G. 2000. Gene Ontology: tool for the unification of biology. NATURE GENETICS 25:25-29. 10.1038/75556

Badri, D.V., Loyola-Vargas, V.M., Broeckling, C.D., De-la-Peña, C., Jasinski, M., Santelia, D., Martinoia, E., Sumner, L.W., Banta, L.M., Stermitz, F., and Vivanco, J.M. 2008. Altered Profile of Secondary Metabolites in the Root Exudates of Arabidopsis ATP-Binding Cassette Transporter Mutants. PLANT PHYSIOLOGY 146:762-771. 10.1104/pp.107.109587

Badri, D.V., Loyola-Vargas, V.M., Du, J., Stermitz, F.R., Broeckling, C.D., Iglesias-Andreu, L., and Vivanco, J.M. 2008. Transcriptome analysis of Arabidopsis roots treated with signaling compounds: a focus on signal transduction, metabolic regulation and secretion. $N E W$ PHYTOLOGIST 179:209-223. 10.1111/j.1469-8137.2008.02458.x

Bailey, T.L., and Elkan, C. 1994. Fitting a mixture model by expectation maximization to discover motifs in biopolymers. Proceedings. International Conference on Intelligent Systems for Molecular Biology 2:28-36.

Bird, D., Beisson, F., Brigham, A., Shin, J., Greer, S., Jetter, R., Kunst, L., Wu, X., Yephremov, A., and Samuels, L. 2007. Characterization of Arabidopsis ABCG11/WBC11, an ATP binding cassette $(\mathrm{ABC})$ transporter that is required for cuticular lipid secretion. PLANT JOURNAL 52:485498. 10.1111/j.1365-313X.2007.03252.x

Chen. 2018. TBtools, a Toolkit for Biologists integrating various biological data handling tools with a user-friendly interface. 10.1101/289660

Chen, G., Komatsuda, T., Ma, J.F., Nawrath, C., Pourkheirandish, M., Tagiri, A., Hu, Y.G., Sameri, M., Li, X., Zhao, X., Liu, Y., Li, C., Ma, X., Wang, A., Nair, S., Wang, N., Miyao, A., Sakuma, S., Yamaji, N., Zheng, X., and Nevo, E. 2011. An ATP-binding cassette subfamily G full transporter is essential for the retention of leaf water in both wild barley and rice. Proc Natl Acad Sci U S A 108:12354-12359. 10.1073/pnas.1108444108

490 Chou, K., and Shen, H. 2008. Cell-PLoc: a package of Web servers for predicting subcellular 491 localization of proteins in various organisms. Nature Protocols 3:153-162. 
492

493

494

495

496

497

498

499

500

501

502

503

504

505

506

507

508

509

510

511

512

513

514

515

516

517

518

519

520

521

522

523

10.1038/nprot.2007.494

Consortium, T.G.O. 2019. The Gene Ontology Resource: 20 years and still GOing strong. NUCLEIC ACIDS RESEARCH 47:D330-D338. 10.1093/nar/gky1055

Davidson, A.L., and Maloney, P.C. 2007. ABC transporters: how small machines do a big job. TRENDS IN MICROBIOLOGY 15:448-455. 10.1016/j.tim.2007.09.005

Dudler, R., and Hertig, C. 1992. Structure of an mdr-like gene from Arabidopsis thaliana. Evolutionary implications. JOURNAL OF BIOLOGICAL CHEMISTRY 267:5882-5888.

Ehlert, A., Weltmeier, F., Wang, X., Mayer, C.S., Smeekens, S., Vicente-Carbajosa, J., and DrögeLaser, W. 2006. Two-hybrid protein-protein interaction analysis in Arabidopsis protoplasts: establishment of a heterodimerization map of group $\mathrm{C}$ and group S bZIP transcription factors. The Plant Journal 46:890-900. 10.1111/j.1365-313X.2006.02731.x

Etc., T.H.T.D. 2018. Functions of ABC transporters in plant growth and development Thanh Ha Thi Do1, Enrico Martinoia2 and Youngsook Lee1. PLANT BIOLOGY.

Farooq, M., Wahid, A., Kobayashi, N., Fujita, D., and Basra, S.M.A. 2009. Plant drought stress: effects, mechanisms and management. Agronomy for Sustainable Development 29:185-212. 10.1051/agro:2008021

Fourcroy, P., Siso-Terraza, P., Sudre, D., Saviron, M., Reyt, G., Gaymard, F., Abadia, A., Abadia, J., Alvarez-Fernandez, A., and Briat, J.F. 2014. Involvement of the ABCG37 transporter in secretion of scopoletin and derivatives by Arabidopsis roots in response to iron deficiency. $N E W$ PHYTOLOGIST 201:155-167. 10.1111/nph.12471

Goodman, C.D., Casati, P., and Walbot, V. 2004. A multidrug resistance-associated protein involved in anthocyanin transport in Zea mays. PLANT CELL 16:1812-1826. 10.1105/tpc.022574

H Shepherd, R.B. 1986. Moisture-dependent Physical Properties of Pigeon Pea. Journal of Agricultural Engineering Research.

Hashimoto, T., and Yamada, Y. 2003. New genes in alkaloid metabolism and transport. Curr Opin Biotechnol 14:163-168.

Hyde, S.C., Emsley, P., Hartshorn, M.J., Mimmack, M.M., Gileadi, U., Pearce, S.R., Gallagher, M.P., Gill, D.R., Hubbard, R.E., and Higgins, C.F. 1990. Structural model of ATP-binding proteins associated with cystic fibrosis, multidrug resistance and bacterial transport. NATURE 346:362365. $10.1038 / 346362 \mathrm{a} 0$

Imai, Y., Tsukahara, S., Asada, S., and Sugimoto, Y. 2004. Phytoestrogens/flavonoids reverse breast cancer resistance protein/ABCG2-mediated multidrug resistance. CANCER RESEARCH 
524

525

526

527

528

529

530

531

532

533

534

535

536

537

538

539

540

541

542

543

544

545

546

547

548

549

550

551

552

553

554

555

64:4346-4352. 10.1158/0008-5472.CAN-04-0078

J. E. Walker, M.S.M.J. 1982. Distantly related sequences in the alpha-and beta-subunits of ATP synthase, myosin, kinases and ther ATP-requiring enzymes Distantly related sequences in the alpha - and beta - subunits of ATP synthase, myosin, kinases and other ATP - requiring enzymes and a common nucleotide binding fold. EMBO J (1982)1:945-951.

Jasinski, M., Banasiak, J., Radom, M., Kalitkiewicz, A., and Figlerowicz, M. 2009. Full-size ABC transporters from the ABCG subfamily in medicago truncatula. Mol Plant Microbe Interact 22:921-931. 10.1094/MPMI-22-8-0921

Jasinski, M., Ducos, E., Martinoia, E., and Boutry, M. 2003. The ATP-binding cassette transporters: structure, function, and gene family comparison between rice and Arabidopsis. PLANT PHYSIOLOGY 131:1169-1177. 10.1104/pp.102.014720

Kang, J., Hwang, J., Lee, M., Kim, Y., Assmann, S.M., Martinoia, E., and Lee, Y. 2010. PDRtype $\mathrm{ABC}$ transporter mediates cellular uptake of the phytohormone abscisic acid. Proceedings of the National Academy of Sciences 107:2355-2360. 10.1073/pnas.0909222107

Kang, J., Park, J., Choi, H., Burla, B., Kretzschmar, T., Lee, Y., and Martinoia, E. 2011. Plant ABC Transporters. Arabidopsis Book 9:e153. 10.1199/tab.0153

Kim, D.Y., Bovet, L., Maeshima, M., Martinoia, E., and Lee, Y. 2007. The ABC transporter AtPDR8 is a cadmium extrusion pump conferring heavy metal resistance. PLANT JOURNAL 50:207-218. 10.1111/j.1365-313X.2007.03044.x

Kim, D.Y., Jin, J.Y., Alejandro, S., Martinoia, E., and Lee, Y. 2010. Overexpression of AtABCG36 improves drought and salt stress resistance in Arabidopsis. Physiol Plant 139:170180. 10.1111/j.1399-3054.2010.01353.x

Kretzschmar, T., Burla, B., Lee, Y., Martinoia, E., and Nagy, R. 2011. Functions of ABC transporters in plants. Essays in Biochemistry 50:145-160. 10.1042/bse0500145

KUBIS, S., SCHMIDT, T., and HESLOP-HARRISON, J.S.P. 1998. Repetitive DNA Elements as a Major Component of Plant Genomes. ANNALS OF BOTANY 82:45-55. https://doi.org/10.1006/anbo.1998.0779

Kuromori, T., Miyaji, T., Yabuuchi, H., Shimizu, H., Sugimoto, E., Kamiya, A., Moriyama, Y., and Shinozaki, K. 2010. ABC transporter AtABCG25 is involved in abscisic acid transport and responses. Proceedings of the National Academy of Sciences 107:2361-2366. 10.1073/pnas.0912516107

Kuromori, T., Sugimoto, E., and Shinozaki, K. 2011. Arabidopsis mutants of AtABCG22, an ABC 
556 transporter gene, increase water transpiration and drought susceptibility. PLANT JOURNAL $557 \quad 67: 885-894.10 .1111 / \mathrm{j} .1365-313 X .2011 .04641 . x$

558 Le Hir, R., Sorin, C., Chakraborti, D., Moritz, T., Schaller, H., Tellier, F., Robert, S., Morin, H., 559 Bako, L., and Bellini, C. 2013. ABCG9, ABCG11 and ABCG14 ABC transporters are required 560 for vascular development in Arabidopsis. The Plant Journal 76:811-824. 10.1111/tpj.12334

561 Lee, I., Ambaru, B., Thakkar, P., Marcotte, E.M., and Rhee, S.Y. 2010. Rational association of 562 
588 Mosser, J., Douar, A.M., Sarde, C.O., Kioschis, P., Feil, R., Moser, H., Poustka, A.M., Mandel, 589 J.L., and Aubourg, P. 1993. Putative X-linked adrenoleukodystrophy gene shares unexpected 590 homology with ABC transporters. NATURE 361:726-730. 10.1038/361726a0

591 Mourez, M., Hofnung, M., and Dassa, E. 1997. Subunit interactions in ABC transporters: a 592 conserved sequence in hydrophobic membrane proteins of periplasmic permeases defines an important site of interaction with the ATPase subunits. EMBO JOURNAL 16:3066-3077. 10.1093/emboj/16.11.3066

Mukherjee, D., Saha, D., Acharya, D., Mukherjee, A., Chakraborty, S., and Ghosh, T.C. 2018. The role of introns in the conservation of the metabolic genes of Arabidopsis thaliana. GENOMICS 110:310-317. 10.1016/j.ygeno.2017.12.003

Ogoda, O.J., Akubue, P.I., and Okide, G.B. 2002. The kinetics of reversal of pre-sickled erythrocytes by the aqueous extract of Cajanus cajan seeds. PHYTOTHERAPY RESEARCH 16:748-750. 10.1002/ptr.1026

Pandey, P.C., and Pandey, V. 1991. Urease purification from the seeds of Cajanus cajan and its application in a biosensor construction. Appl Biochem Biotechnol 31:247-251.

Panikashvili, D., Savaldi-Goldstein, S., Mandel, T., Yifhar, T., Franke, R.B., Höfer, R., Schreiber, L., Chory, J., and Aharoni, A. 2007a. The Arabidopsis DESPERADO/AtWBC11 Transporter Is Required for Cutin and Wax Secretion. PLANT PHYSIOLOGY 145:1345-1360. 10.1104/pp.107.105676

607 Potter, S.C., Luciani, A., Eddy, S.R., Park, Y., Lopez, R., and Finn, R.D. 2018. HMMER web server: 2018 update. NUCLEIC ACIDS RESEARCH 46:W200-W204. 10.1093/nar/gky448

Rombauts, S., Dehais, P., Van Montagu, M., and Rouze, P. 1999. PlantCARE, a plant cis-acting regulatory element database. NUCLEIC ACIDS RESEARCH 27:295-296. 10.1093/nar/27.1.295

611 Rose, A.B., Carter, A., Korf, I., and Kojima, N. 2016. Intron sequences that stimulate gene 612 expression in Arabidopsis. PLANT MOLECULAR BIOLOGY 92:337-346. 10.1007/s11103-016$613 \quad 0516-1$

614 Sanchez-Fernandez, R., Davies, T.G., Coleman, J.O., and Rea, P.A. 2001. The Arabidopsis 615 thaliana ABC protein superfamily, a complete inventory. JOURNAL OF BIOLOGICAL 616 CHEMISTRY 276:30231-30244. 10.1074/jbc.M103104200

617 Schneider, E., and Hunke, S. 1998. ATP-binding-cassette (ABC) transport systems: functional and 618 structural aspects of the ATP-hydrolyzing subunits/domains. FEMS MICROBIOLOGY REVIEWS 619 22:1-20. 10.1111/j.1574-6976.1998.tb00358.x

620 Schulz, B., and Kolukisaoglu, H.U. 2006. Genomics of plant ABC transporters: the alphabet of 
621 photosynthetic life forms or just holes in membranes? FEBS LETTERS 580:1010-1016. 622 10.1016/j.febslet.2006.01.002

623 Singh, A.K., Rai, V.P., Chand, R., Singh, R.P., and Singh, M.N. 2013. Genetic diversity studies and identification of SSR markers associated with Fusarium wilt (Fusariumudum) resistance in cultivated pigeonpea (Cajanus cajan). JOURNAL OF GENETICS 92:273-280.

626 Tamura, K., Stecher, G., Peterson, D., Filipski, A., and Kumar, S. 2013. MEGA6: Molecular 627 Evolutionary Genetics Analysis Version 6.0. MOLECULAR BIOLOGY AND EVOLUTION 628 30:2725-2729. 10.1093/molbev/mst197

629 Toledo, M.A., Schneider, D.R., Azzoni, A.R., Favaro, M.T., Pelloso, A.C., Santos, C.A., Saraiva, 630 A.M., and Souza, A.P. 2011. Characterization of an oxidative stress response regulator, 631 homologous to Escherichia coli OxyR, from the phytopathogen Xylella fastidiosa. Protein Expr 632 Purif 75:204-210. 10.1016/j.pep.2010.10.004

633

634

635

636

van den Brule, S., Muller, A., Fleming, A.J., and Smart, C.C. 2002. The ABC transporter SpTUR2 confers resistance to the antifungal diterpene sclareol. PLANT JOURNAL 30:649-662.

van den Brule, S., and Smart, C.C. 2002. The plant PDR family of ABC transporters. PLANTA 216:95-106. 10.1007/s00425-002-0889-z

Varshney, R.K., Chen, W., Li, Y., Bharti, A.K., Saxena, R.K., Schlueter, J.A., Donoghue, M.T., Azam, S., Fan, G., Whaley, A.M., Farmer, A.D., Sheridan, J., Iwata, A., Tuteja, R., Penmetsa, R.V., Wu, W., Upadhyaya, H.D., Yang, S.P., Shah, T., Saxena, K.B., Michael, T., McCombie, W.R., Yang, B., Zhang, G., Yang, H., Wang, J., Spillane, C., Cook, D.R., May, G.D., Xu, X., and Jackson, S.A. 2011. Draft genome sequence of pigeonpea (Cajanus cajan), an orphan legume crop of resource-poor farmers. NATURE BIOTECHNOLOGY 30:83-89. 10.1038/nbt.2022

Verrier, P.J., Bird, D., Burla, B., Dassa, E., Forestier, C., Geisler, M., Klein, M., Kolukisaoglu, U., Lee, Y., Martinoia, E., Murphy, A., Rea, P.A., Samuels, L., Schulz, B., Spalding, E.J., Yazaki, K., and Theodoulou, F.L. 2008. Plant ABC proteins--a unified nomenclature and updated inventory. TRENDS IN PLANT SCIENCE 13:151-159. 10.1016/j.tplants.2008.02.001

Voorrips, R.E. 2002. MapChart: software for the graphical presentation of linkage maps and QTLs. JOURNAL OF HEREDITY 93:77-78. 10.1093/jhered/93.1.77

Wu, G., Lewis, D.R., and Spalding, E.P. 2007. Mutations inArabidopsis Multidrug ResistanceLike ABC Transporters Separate the Roles of Acropetal and Basipetal Auxin Transport in Lateral Root Development. The Plant Cell 19:1826-1837. 10.1105/tpc.106.048777

Wu, N., Kong, Y., Fu, Y., Zu, Y., Yang, Z., Yang, M., Peng, X., and Efferth, T. 2011. In vitro antioxidant properties, DNA damage protective activity, and xanthine oxidase inhibitory effect of 
654 cajaninstilbene acid, a stilbene compound derived from pigeon pea [Cajanus cajan (L.) Millsp.] 655 leaves. J Agric Food Chem 59:437-443. 10.1021/jf103970b

656 Yadu, B., Chandrakar, V., Korram, J., Satnami, M.L., Kumar, M., and S, K. 2018. Silver 657 nanoparticle modulates gene expressions, glyoxalase system and oxidative stress markers in 658 fluoride stressed Cajanus cajan L. JOURNAL OF HAZARDOUS MATERIALS 353:44-52. 659 10.1016/j.jhazmat.2018.03.061

660 Yang, X., Coulombe-Huntington, J., Kang, S., Sheynkman, G.M., Hao, T., Richardson, A., Sun, 661 S., Yang, F., Shen, Y.A., Murray, R.R., Spirohn, K., Begg, B.E., Duran-Frigola, M., MacWilliams, 662 A., Pevzner, S.J., Zhong, Q., Trigg, S.A., Tam, S., Ghamsari, L., Sahni, N., Yi, S., Rodriguez, 663 M.D., Balcha, D., Tan, G., Costanzo, M., Andrews, B., Boone, C., Zhou, X.J., Salehi-Ashtiani, K., 664 Charloteaux, B., Chen, A.A., Calderwood, M.A., Aloy, P., Roth, F.P., Hill, D.E., Iakoucheva, 665 L.M., Xia, Y., and Vidal, M. 2016. Widespread Expansion of Protein Interaction Capabilities by 666 Alternative Splicing. CELL 164:805-817. 10.1016/j.cell.2016.01.029

667 Yazaki, K. 2006. ABC transporters involved in the transport of plant secondary metabolites. FEBS 668 LETTERS 580:1183-1191. 10.1016/j.febslet.2005.12.009 


\section{Figure 1}

Phylogenetic analysis of the ABCG transporters among pigeon pea.

Using the MEGA6.0 program, the NJ (Neighbor-Joining, NJ) tree was constructed using the amino acid sequence of the pigeon pea ABCG transporters. The numbers beside the branches represent bootstrap values based on 1000 replications. The outer side of the phylogenetic tree is a branch labeled with two subgroups of the pigeon pea ABCG transporters, and shown in different colors. WBC: white-brown complex; PDR: pleiotropic drug resistance. 


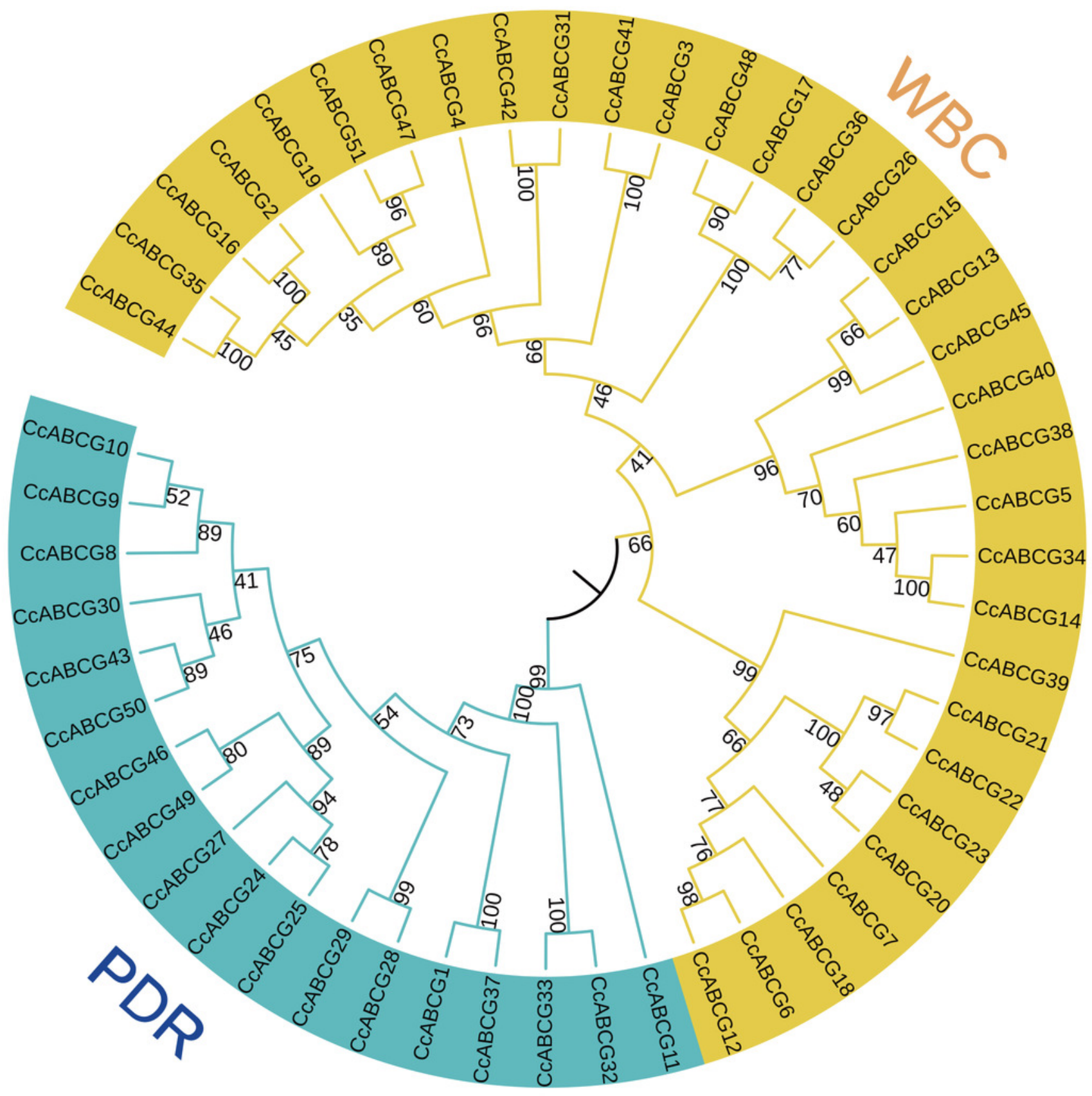


Figure 2

The chromosomal location of the pigeon pea $A B C G$ genes.

The pigeon pea $A B C G$ genes were named $C C A B C G 1-C C A B C G 51$ based on chromosomal location information. All of $A B C G$ genes were location in all pigeon pea chromosomal except of chromosomal 7. ChrUn contained 17 members, which were mapped based on the length of those unplaced scaffold sequences with 17 genes, respectively. 

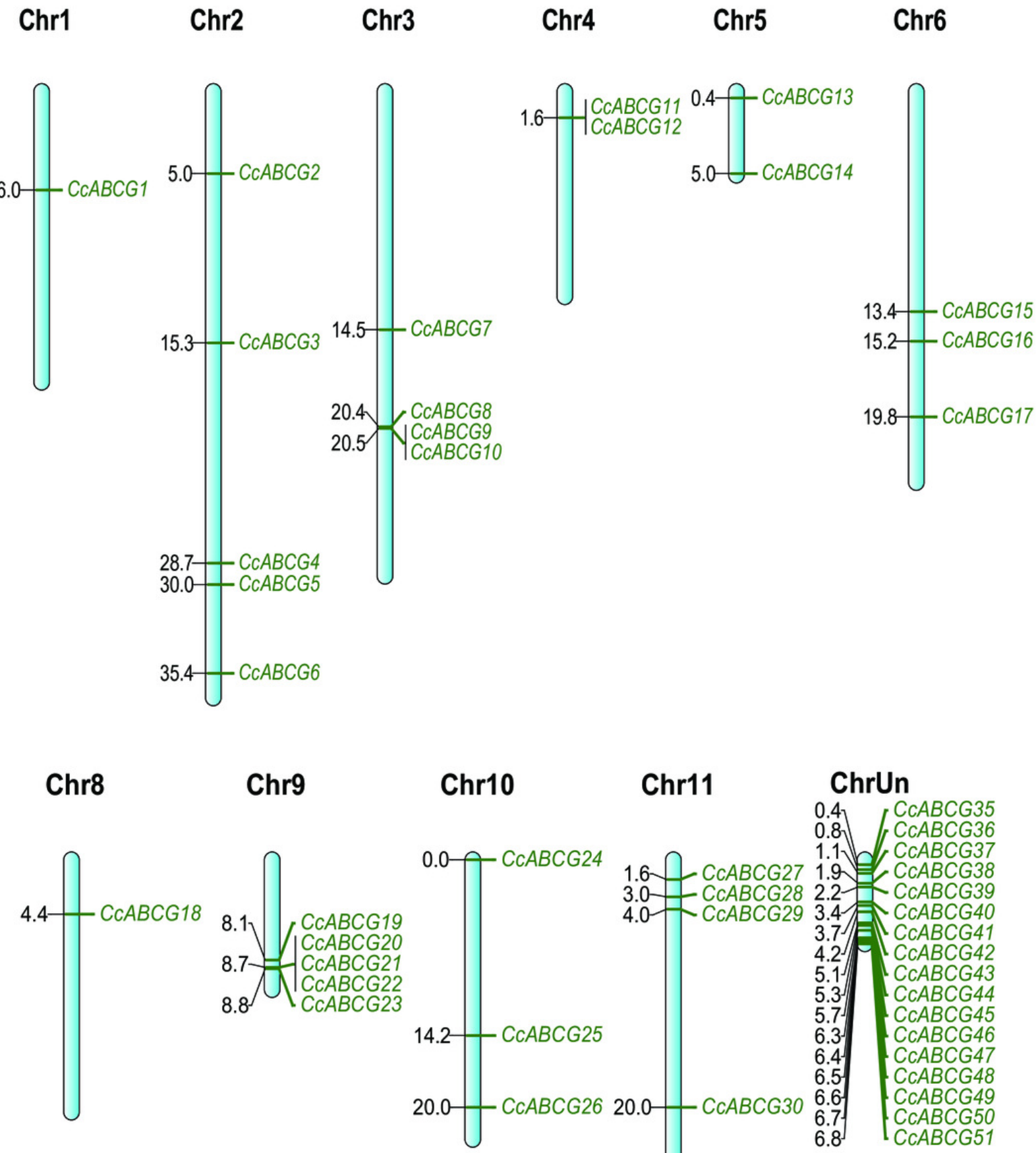

\section{Chr11}

\section{ChrUn}

$0.4 \quad$ CCABCG35

0.8 CCABCG36

1.1 $\mathrm{CCABCG} 37$

1.6 CCABCG27 1.9 $\cong$ CCABCG38

$3.0-C C A B C G 28$ 2.2- CCABCG39

4.0 CCABCG29 3.4 $=$ CCABCG40

3.7/ $=$ CCABCG41

4.2 - CCABCG42

5.1 $\mathrm{C} C \mathrm{ABCG} 43$

5.3 $\mathrm{C} C \mathrm{ABCG} 44$

5.7 $C C A B C G 45$

6.3 - CCABCG46

6.4

CCABCG47

$20.0-1 C A B C G 30 \begin{array}{ll}6.5 \\ 6.7 \\ 6.7 \\ 6.8\end{array}-\begin{aligned} & 6.4 \\ & \text { CCABCG48 } \\ & \text { CCABCG49 } \\ & \text { CCABCG50 } \\ & \text { CCABCG51 }\end{aligned}$

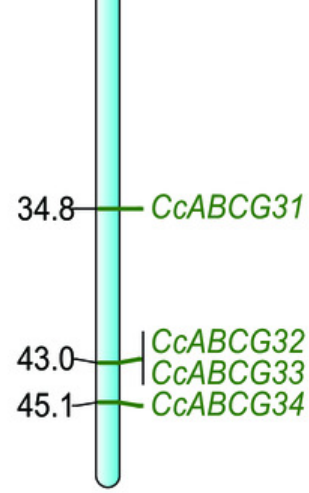


Figure 3

Motifs and conserved domain of CCABCGs.

(A) The 10 conserved motif of CCABCGs on the MEME software. Motif annotation is shown as color legends. Annotates of motif were listed on the Supplemental Table S3. (B) Conserved domain of CCABCGs. Blue indicates the NBD (nucleotide binding domain), and orange indicates the another conserved domain TMD (trans-membrane domains). 

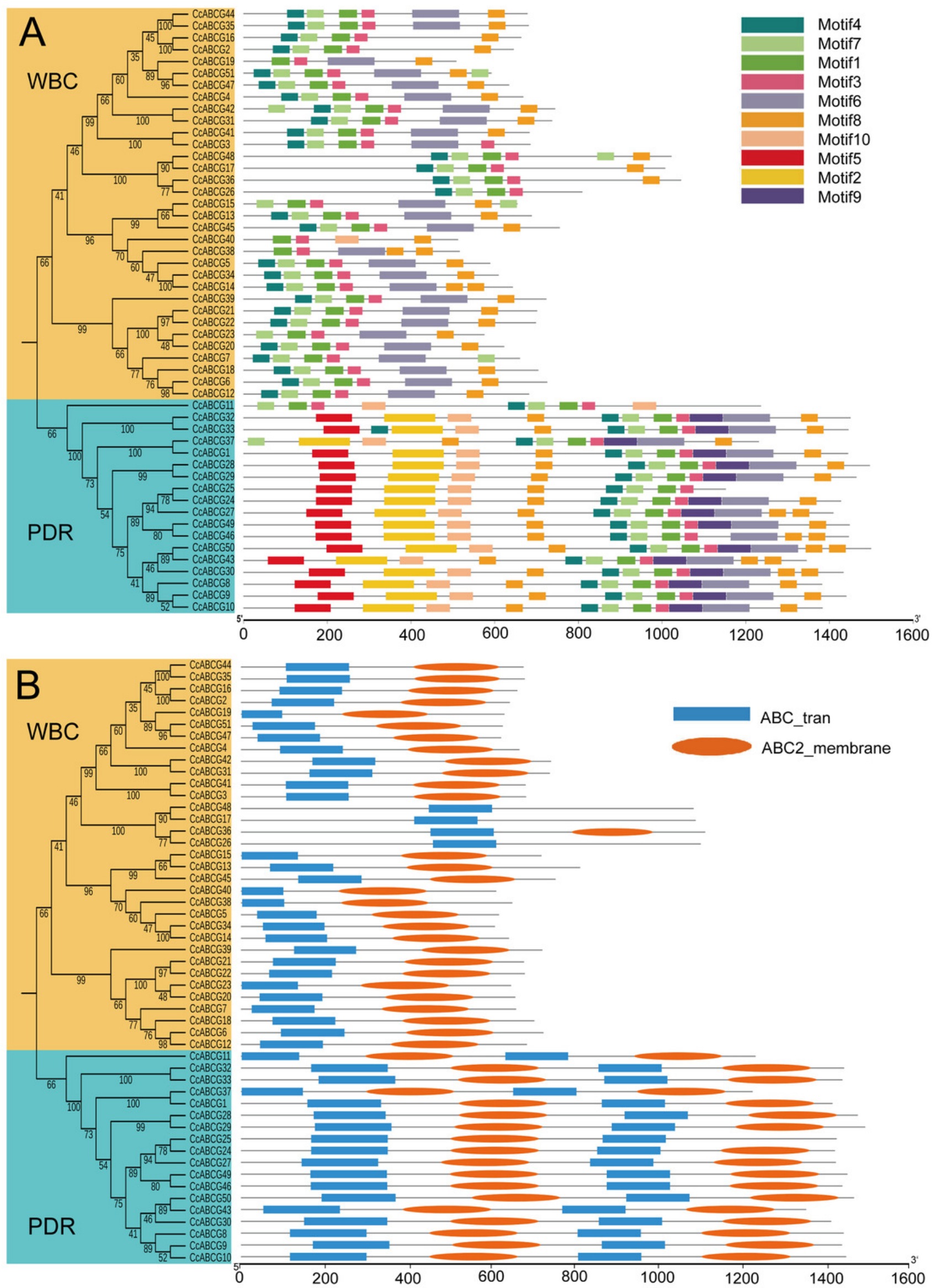
Figure 4

Gene structure and cis-elements analysis of $A B C G$ genes.

(A) Intron-exon structures of CCABCG genes. Yellow rectangles: coding sequences (CDSs); thin lines: introns; blue rectangles: untranslated regions (UTRs). (B) Putative regulatory ciselements in the $A B C G$ gene promoters. The relative positions of elements are labeled with capital letters in the figure. 


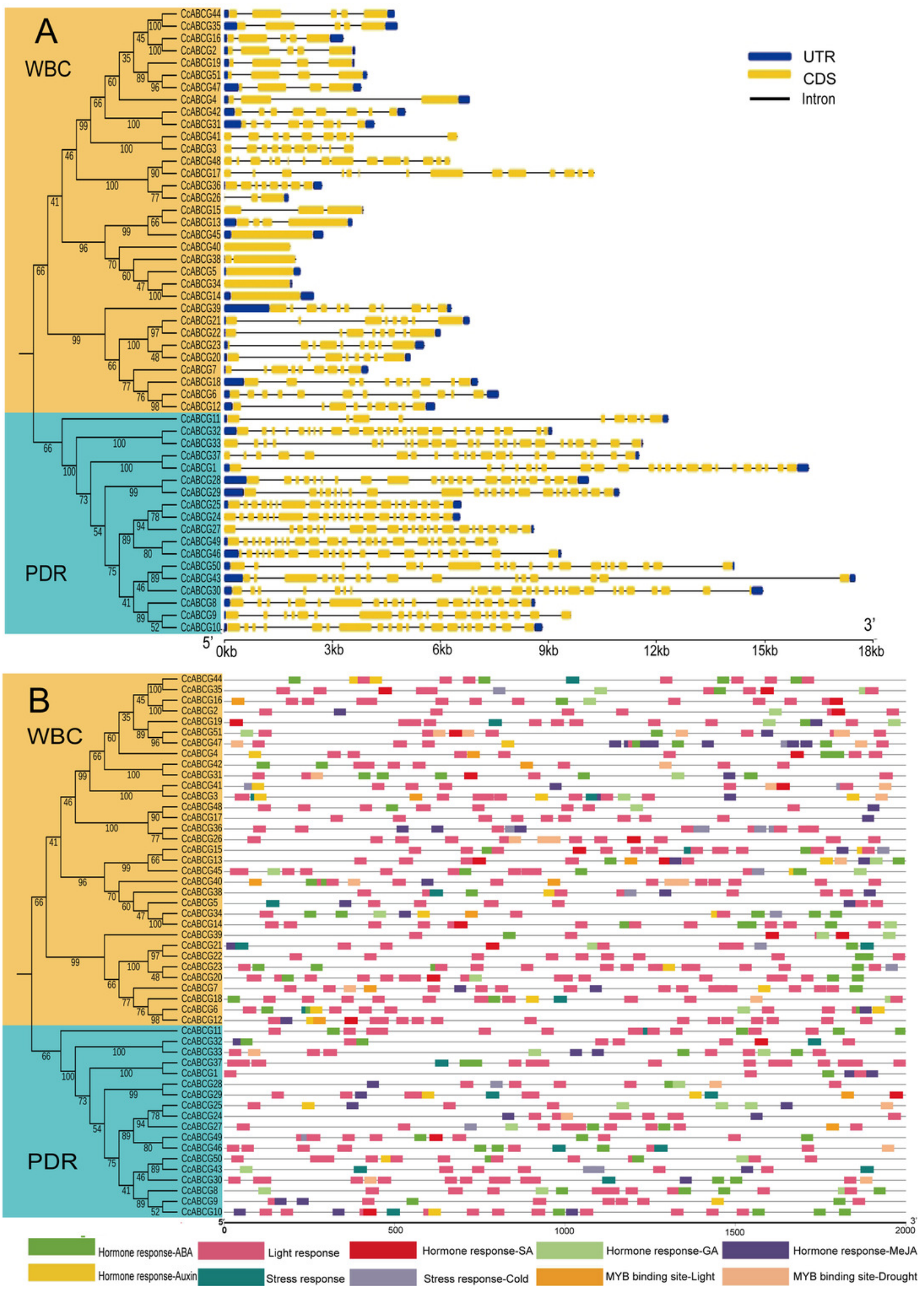

Peer) reviewing PDF | (2019:10:42565:6:0:NEW 4 Dec 2020) 
Figure 5

Go annotation of ABCG transporters in pigeon pea

GO annotations of ABCG transporters in pigeon pea were predicted using Swiss-prot database serve. Red means molecular function, yellow means cell component and blue means biological process. Displaying only results for FDR $P<0.05$ 


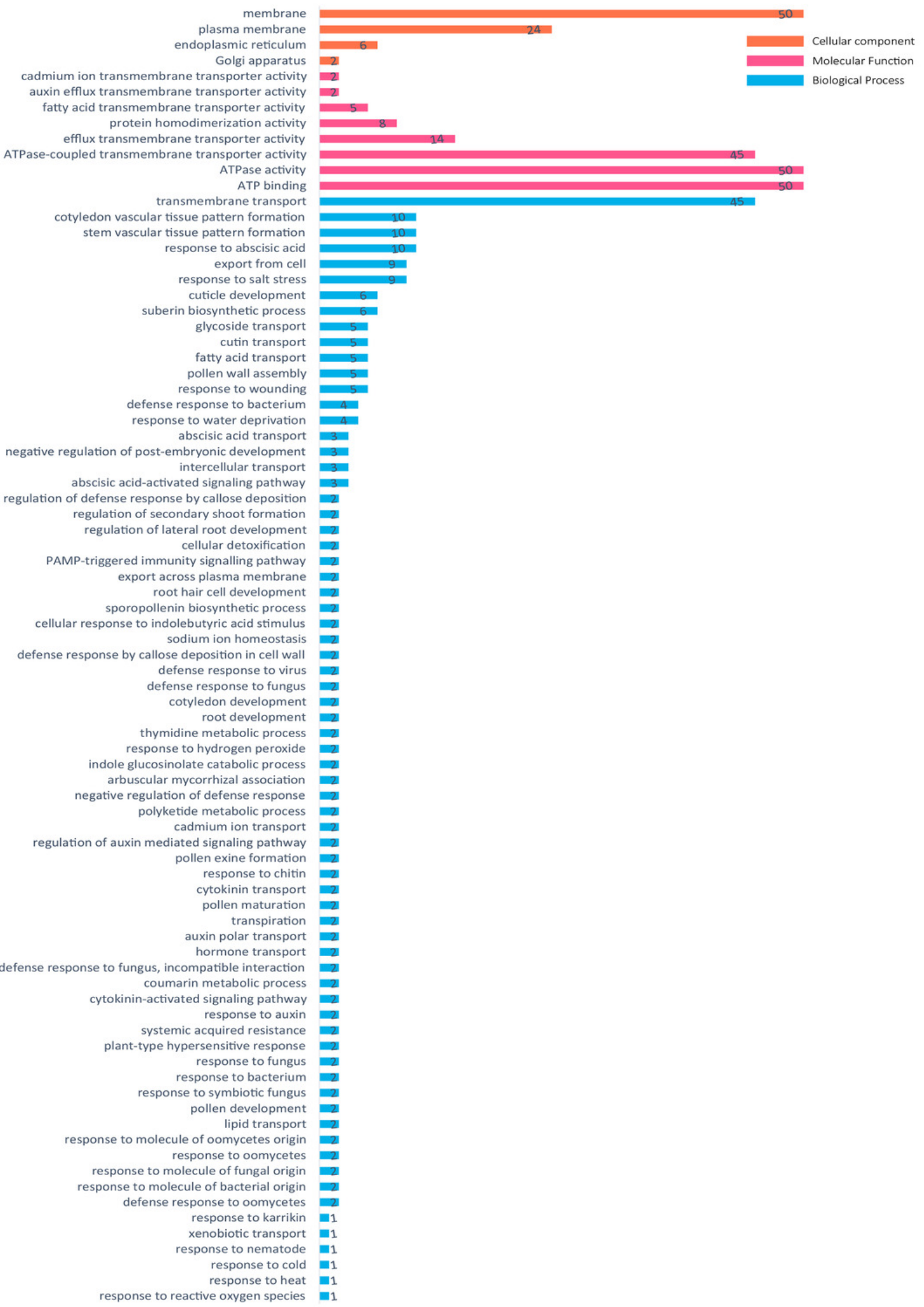

Peer] reviewing PDF | (2019:10:42565:6:0:NEW 4 Dec 2020) 


\section{Figure 6}

Expression analysis of pigeon pea $A B C G$ gene in different organs.

The expression levels of 10 genes in different tissues are shown in the heat map. Three biological replicates per sample. Values represent means \pm SEM.

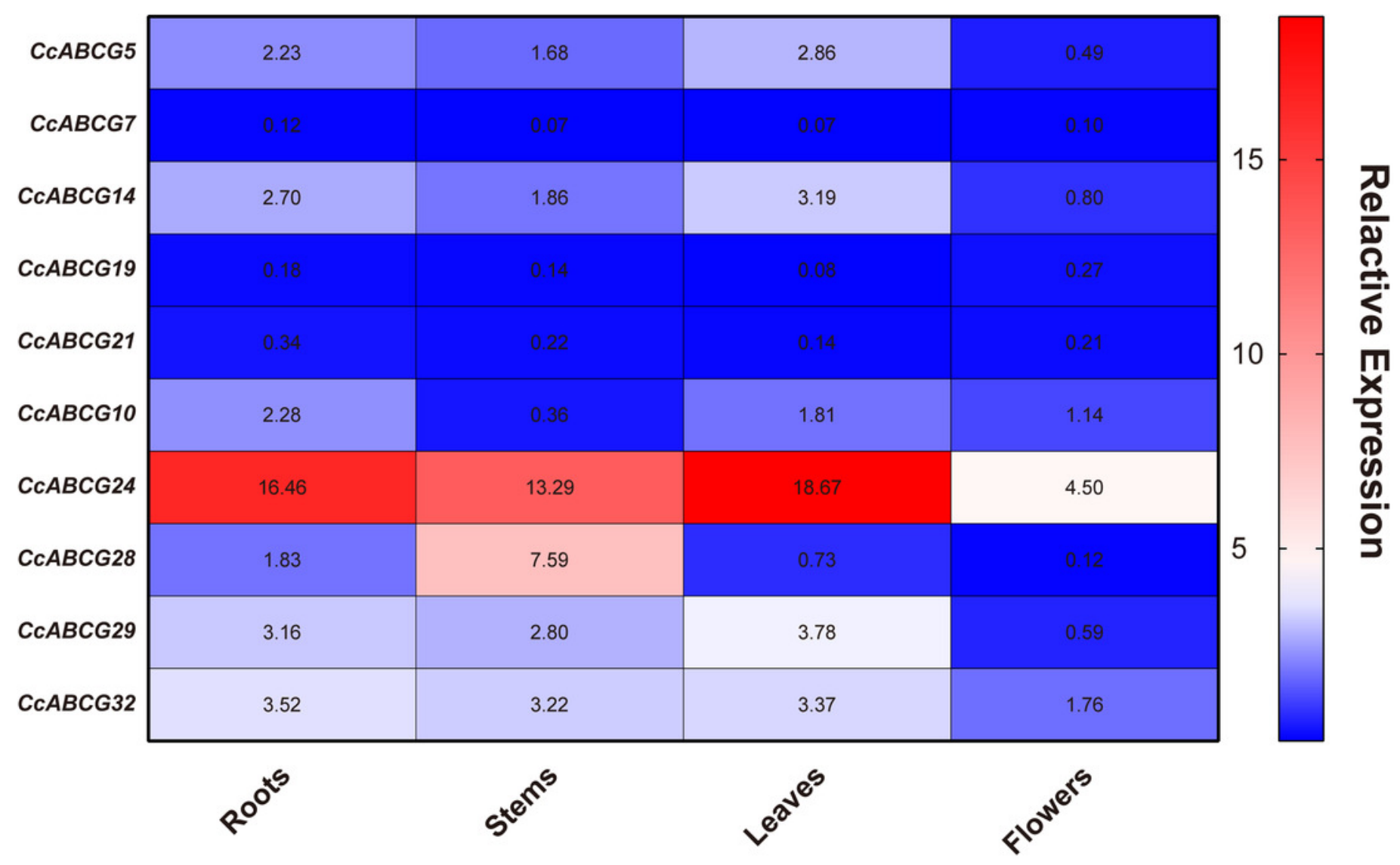




\section{Figure 7}

Relative expression analysis of the pigeon pea $A B C G$ genes under different abiotic stresses.

Relative expression level of the $A B C G$ genes in pigeon pea under different abiotic stresses of $4^{\circ} \mathrm{C}(\mathrm{A}, \mathrm{B}), 42^{\circ} \mathrm{C}(\mathrm{C}, \mathrm{D}), 250 \mathrm{nmol} / \mathrm{L}$ mannitol $(\mathrm{E}, \mathrm{F}), 100 \mu \mathrm{mo} / \mathrm{L} \mathrm{AlCl}{ }_{3}(\mathrm{G}, \mathrm{H}), 200 \mathrm{nmol} / \mathrm{L} \mathrm{NaCl}$

$(\mathrm{I}, \mathrm{J})$. Expression analysis was performed using a relative quantitative method ${ }^{2-\Delta \Delta \mathrm{Ca}}$, and CCActin as internal reference gene. Relative expression level of roots: $A, C, E, G, I ;$ relative expression level of leaves: B,D,F,H,J.Three biological replicates of each sample. Values represent means \pm SEM. Asterisks indicate significant difference as determined by Dunnett's multiple comparisons test $(* *, P<0.01)$. n.s., no significant difference. 

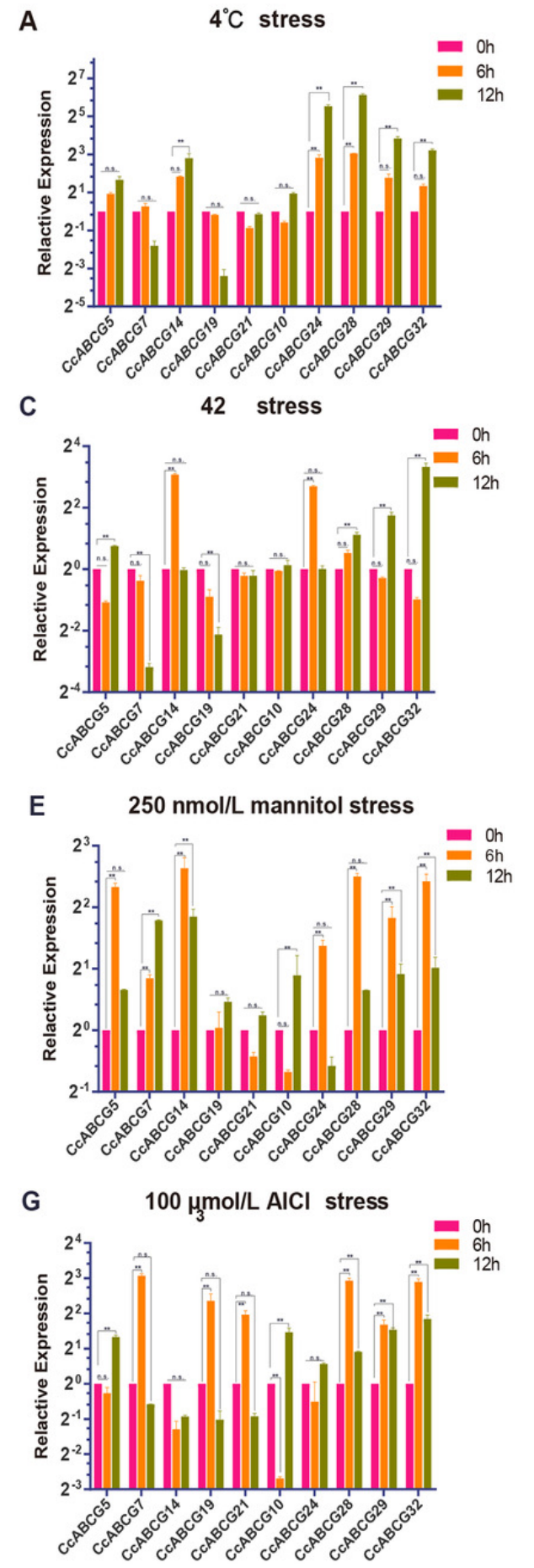

I $200 \mathrm{nmol} / \mathrm{L} \mathrm{NaCl}$ stress

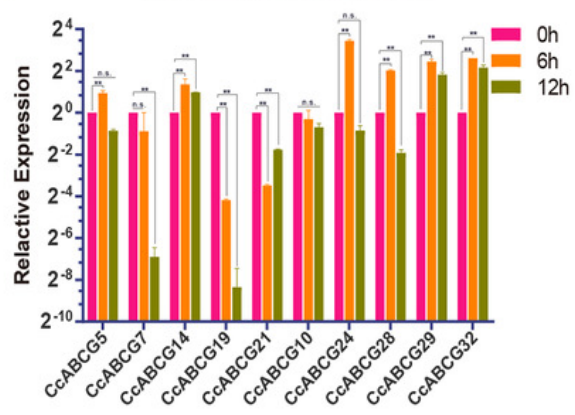

B $\quad 4^{\circ} \mathrm{C}$ stress

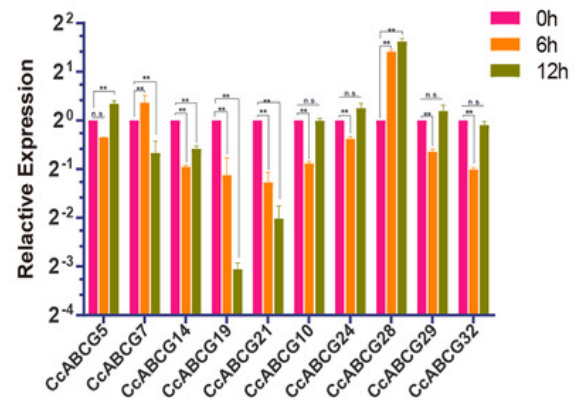

D

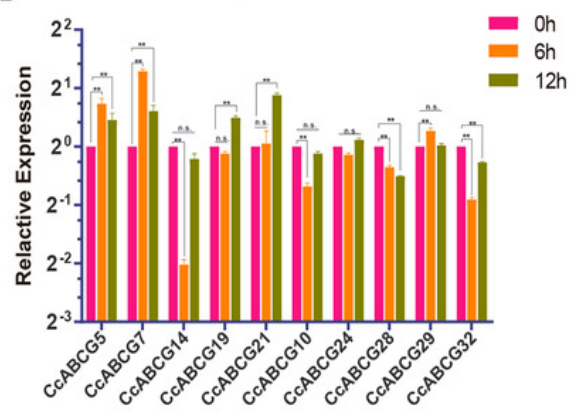

$\mathbf{F}$
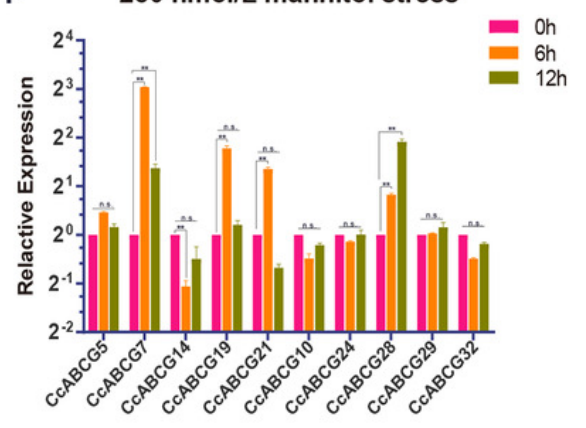

$\mathrm{H}$

$100 \mu \mathrm{mol} / \mathrm{L} \mathrm{AlCl}_{3}$ stress

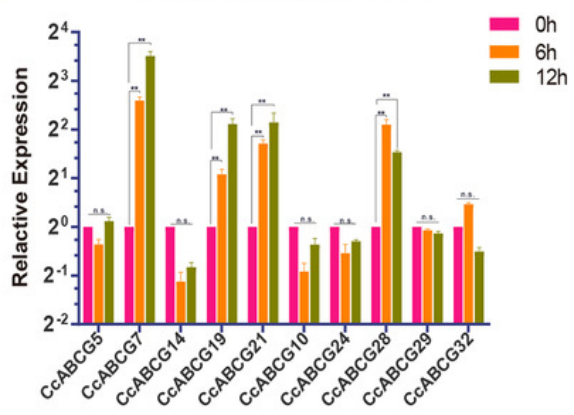

J

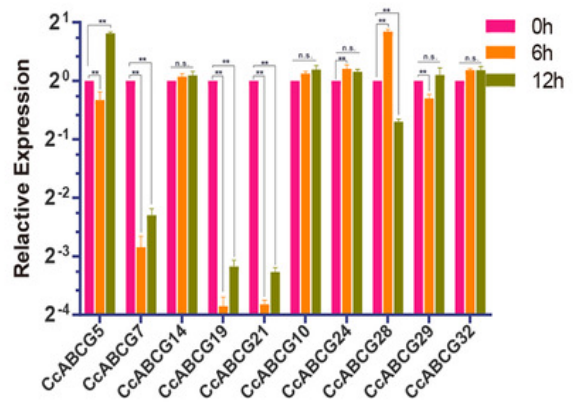




\section{Table $\mathbf{1}$ (on next page)}

Prediction of physicochemical properties and subcellular localization of ABCG transporters. 


\section{Table 1.}

Prediction of physicochemical properties and subcellular localization of ABCG transporters.

\begin{tabular}{|c|c|c|c|c|c|c|c|c|c|}
\hline Gene & Accession & Location & Position & $\begin{array}{c}\text { Length } \\
\text { (aa) }\end{array}$ & Mw & pl & Chr & Exon & Sub-loc \\
\hline$C c A B C G 1$ & KYP76113 & LOC 109804364 & $6006382-6022606$ & 1421 & 159155.33 & 7.76 & 1 & 23 & Cell membrane \\
\hline$C c A B C G 2$ & KYP72481 & LOC 109789679 & $5026814-5030449$ & 645 & 72010.85 & 9.08 & 2 & 5 & Cell membrane \\
\hline$C c A B C G 3$ & KYP73490 & LOC109810734 & $\begin{array}{l}15320209- \\
15323794\end{array}$ & 684 & 77318.74 & 8.11 & 2 & 10 & Cell membrane \\
\hline$C c A B C G 4$ & KYP74721 & LOC 109795335 & $\begin{array}{c}28723419- \\
28730237\end{array}$ & 668 & 73512.6 & 9.47 & 2 & 3 & Cell membrane \\
\hline$C c A B C G 5$ & KYP74838 & LOC 109806747 & $\begin{array}{r}29968224- \\
29970344\end{array}$ & 619 & 69012.83 & 9.4 & 2 & 1 & Cell membrane \\
\hline CcABCG6 & KYP75362 & LOC109815813 & $\begin{array}{c}35437420- \\
35445042\end{array}$ & 726 & 79570.36 & 8.27 & 2 & 12 & Cell membrane \\
\hline$C c A B C G 7$ & KYP70503 & LOC 109797228 & $\begin{array}{c}14492247- \\
14496242\end{array}$ & 660 & 73883.51 & 8.81 & 3 & 9 & Cell membrane \\
\hline$C c A B C G 8$ & KYP71088 & LOC 109796083 & $\begin{array}{c}20447829- \\
20456456\end{array}$ & 1448 & 164560.21 & 8.28 & 3 & 20 & Cell membrane \\
\hline$C c A B C G^{9}$ & KYP71089 & LOC 109796084 & $\begin{array}{c}20469958- \\
20479590\end{array}$ & 1444 & 163478.51 & 8.27 & 3 & 20 & Cell membrane \\
\hline CcABCG 10 & KYP71090 & LOC 109796805 & $\begin{array}{c}20488744- \\
20497576\end{array}$ & 1454 & 164868.63 & 7.95 & 3 & 20 & Cell membrane \\
\hline$C c A B C G 11$ & KYР68041 & LOC 109798752 & $1617897-1630220$ & 718 & 80600.64 & 9.1 & 4 & 9 & Cell membrane \\
\hline$C c A B C G 12$ & KYР68044 & LOC109798893 & $1641751-1647610$ & 686 & 76872.23 & 8.88 & 4 & 10 & Cell membrane \\
\hline$C c A B C G 13$ & KYP67437 & LOC 109799601 & $355237-358794$ & 814 & 91841.52 & 8.95 & 5 & 6 & Cell membrane \\
\hline$C c A B C G 14$ & KYP67863 & LOC 109799748 & $5000555-5003051$ & 643 & 72113.02 & 7.88 & 5 & 1 & Cell membrane \\
\hline CcABCG 15 & KYР66379 & LOC 109800436 & 13422611- & 721 & 81114.25 & 8.97 & 6 & 3 & Cell membrane \\
\hline
\end{tabular}




\begin{tabular}{|c|c|c|c|c|c|c|c|c|c|}
\hline & & & 13426469 & & & & & & \\
\hline$C c A B C G 16$ & KYР66524 & LOC109801031 & $\begin{array}{c}15158990- \\
15162297\end{array}$ & 663 & 74678.78 & 8.6 & 6 & 5 & Cell membrane \\
\hline CcABCG17 & КYР66999 & LOC 109800523 & $\begin{array}{c}19843419- \\
19853680\end{array}$ & 1092 & 121456.99 & 8.87 & 6 & 14 & Cell membrane \\
\hline CcABCG18 & KYP61725 & LOC109804023 & $4405565-4412603$ & 704 & 78466.57 & 8.83 & 8 & 10 & Cell membrane \\
\hline CcABCG19 & KYP61105 & LOC 109804765 & $8122601-8126214$ & 632 & 70593.09 & 9.02 & 9 & 4 & Cell membrane \\
\hline CcABCG20 & KYP61155 & LOC109805263 & $8663643-8668819$ & 658 & 73428.07 & 7.99 & 9 & 8 & Cell membrane \\
\hline CcABCG21 & KYP61157 & LOC109805167 & $8722014-8728825$ & 679 & 75362.12 & 8.36 & 9 & 8 & Cell membrane \\
\hline CcABCG22 & KYР61159 & LOC109805166 & $8746304-8752313$ & 681 & 75328.34 & 8.65 & 9 & 8 & Cell membrane \\
\hline$C c A B C G 23$ & KYР61160 & LOC109804802 & $8756197-8761747$ & 648 & 71982.39 & 8.81 & 9 & 9 & Cell membrane \\
\hline$C c A B C G 24$ & KYP58337 & LOC109805773 & $11158-17707$ & 1427 & 161183.4 & 7.36 & 10 & 21 & Cell membrane \\
\hline$C c A B C G 25$ & KYP59575 & LOC109805875 & $\begin{array}{l}14201296- \\
14246400\end{array}$ & 1431 & 161968.54 & 7.97 & 10 & 21 & Cell membrane \\
\hline$C c A B C G 26$ & KYР60108 & LOC109805696 & $\begin{array}{l}19992101- \\
20040472\end{array}$ & 1104 & 123273.83 & 8.89 & 10 & 16 & $\begin{array}{c}\text { Cell } \\
\text { membrane. } \\
\text { Chloroplast. }\end{array}$ \\
\hline CcABCG27 & KYP53996 & LOC109808825 & $1626589-1635183$ & 1429 & 162016.24 & 7.32 & 11 & 22 & $\begin{array}{c}\text { Cell membrane } \\
\text { Cell }\end{array}$ \\
\hline CcABCG28 & KYP54148 & LOC109808608 & $3046631-3056753$ & 1482 & 167729.07 & 8.19 & 11 & 23 & $\begin{array}{c}\text { membrane. } \\
\text { Chloroplast. } \\
\text { Cell }\end{array}$ \\
\hline CcABCG29 & KYP54262 & LOC 109807460 & $4014294-4034321$ & 1500 & 170370.83 & 6.75 & 11 & 26 & $\begin{array}{l}\text { membrane. } \\
\text { Chloroplast. }\end{array}$ \\
\hline CcABCG30 & KYP55666 & LOC109807699 & $\begin{array}{l}19989558- \\
20004511\end{array}$ & 1418 & 161820.65 & 8.9 & 11 & 26 & Cell membrane \\
\hline$C c A B C G 31$ & KYP56982 & LOC109809098 & $34818776-$ & 741 & 81702.72 & 9.05 & 11 & 12 & Cell membrane \\
\hline
\end{tabular}




\begin{tabular}{|c|c|c|c|c|c|c|c|c|c|}
\hline & & & 34826902 & & & & & & \\
\hline CcABCG32 & KYP57733 & LOC109807641 & $\begin{array}{c}43015398- \\
43024752\end{array}$ & 1449 & 164070.17 & 7.67 & 11 & 24 & Cell membrane \\
\hline$C c A B C G 33$ & KYP57734 & LOC109809552 & $\begin{array}{c}43027240- \\
43038856\end{array}$ & 1445 & 163218.52 & 8.03 & 11 & 24 & Cell membrane \\
\hline CcABCG34 & KYP57934 & LOC 109807560 & $\begin{array}{l}45075476- \\
45077364\end{array}$ & 609 & 68159.95 & 8.65 & 11 & 1 & Cell membrane \\
\hline CCABCG35 & KYP53034 & LOC109810595 & $391122-395936$ & 681 & 75466.37 & 8.91 & Un & 5 & Cell membrane \\
\hline CcABCG36 & KYP53068 & LOC109810569 & $840758-848796$ & 1115 & 123587.99 & 9.16 & Un & 14 & Cell membrane \\
\hline CcABCG37 & KYP52287 & LOC109811196 & $2121-13637$ & 1229 & 138171.93 & 8.81 & Un & 20 & Cell membrane \\
\hline CCABCG38 & KYP52347 & LOC109811227 & $785413-787392$ & 651 & 73181.09 & 8.45 & Un & 1 & Cell membrane \\
\hline CCABCG39 & KYP51780 & LOC109811628 & $147015-153318$ & 723 & 80384.61 & 8.89 & Un & 12 & Cell membrane \\
\hline CCABCG40 & KYP51380 & LOC109811918 & $541176-543014$ & 612 & 68365.89 & 9.39 & Un & 1 & Cell membrane \\
\hline$C c A B C G 41$ & КYР49769 & LOC109813109 & $127353-133820$ & 683 & 77708.58 & 9.05 & Un & 10 & Cell membrane \\
\hline CcABCG42 & KYP49445 & LOC109813363 & $17796-28760$ & 744 & 82372.18 & 8.91 & Un & 12 & Cell membrane \\
\hline$C c A B C G 43$ & KYP48955 & LOC109813737 & $400317-424748$ & 1358 & 154173.34 & 8.61 & Un & 21 & Cell membrane \\
\hline CcABCG44 & KYP48157 & LOC109814303 & $92212-96948$ & 678 & 75455.58 & 9.06 & Un & 5 & Cell membrane \\
\hline CCABCG45 & KYP47060 & LOC109815112 & $59170-61921$ & 755 & 83546.16 & 9.22 & Un & 1 & Cell membrane \\
\hline$C c A B C G 46$ & KYP41536 & LOC109818995 & 187197-197961 & 1445 & 163678.86 & 8.75 & Un & 24 & Cell membrane \\
\hline$C c A B C G 47$ & KYP39219 & LOC109788852 & $72316-76120$ & 624 & 69345.94 & 8.87 & Un & 4 & Cell membrane \\
\hline CcABCG48 & KYP37548 & LOC109790064 & $6674-12941$ & 1087 & 120433.13 & 8.96 & Un & 14 & Cell membrane \\
\hline CcABCG49 & KYP36564 & LOC109790672 & $14766-22348$ & 1457 & 164896.42 & 8.25 & Un & 24 & Cell membrane \\
\hline CCABCG50 & KYP35274 & LOC109791517 & $44302-58642$ & 1473 & 167555.55 & 7.74 & Un & 20 & Cell membrane \\
\hline CCABCG51 & KYP32835 & LOC109793033 & $5717-9684$ & 628 & 70573.41 & 8.74 & Un & 4 & Cell membrane \\
\hline
\end{tabular}

1 Note.

2 Aa, Amino acid;Mw, Molecular weight;pI, Isoelectric point;Chr, Chromosome; Sub-loc, Subcellular localization. 
